\title{
A density functional theory study on the kinetics of seven-member ring formation in polyaromatic hydrocarbons
}

\author{
Angiras Menon ${ }^{\mathrm{a}, \mathrm{b}}$, Gustavo Leon ${ }^{\mathrm{a}}$, Jethro Akroyd ${ }^{\mathrm{a}, \mathrm{b}}$, Markus Krafta,b,c,* \\ ${ }^{a}$ Department of Chemical Engineering and Biotechnology, University of Cambridge, West \\ Cambridge Site, Philippa Fawcett Drive, Cambridge CB3 0AS, United Kingdom \\ ${ }^{b}$ CARES, Cambridge Centre for Advanced Research and Education in Singapore, 1 Create Way, \\ CREATE Tower, \#05-05, Singapore, 138602 \\ ${ }^{c}$ School of Chemical and Biomedical Engineering, Nanyang Technological University, 62 Nanyang \\ Drive, Singapore, 637459
}

\begin{abstract}
In this work, the kinetics of seven-member ring formation in polycyclic aromatic hydrocarbons (PAHs) containing a five-member ring is studied by density functional theory. The pathways studied include integration of a seven-member ring by the hydrogen-abstraction-acetylene-addition (HACA) mechanism for two different PAHs, one closed shell and one resonance-stabilised-radical (RSR) PAH. The pathways were similar in both cases, but the rate of seven-member ring formation by HACA was seen to be faster for the resonance-stabilised-radical PAH. Formation of a seven member ring by bay closure processes facilitated through hydrogen abstraction, hydrogen addition, carbene formation, and direct cyclisation were also studied for two PAHs. In general, the pathways were rather similar for both PAHs, aside from the direct cyclisation route. The rate constants determined for the pathways were then used in kinetic simulations in OD homogeneous reactors. The results showed that for the RSR PAH, the initial abstraction site is important, with the seven-member ring mainly being formed when abstraction occurs near the five member ring. This was not the case for the closed shell PAH. Additionally, the RSR PAH product was able to undergo an azulene to naphthalene-like transformation at longer timescales. For the bay closures, it was seen for both PAHs that the hydrogen abstraction facilitated bay closures contributes the most to seven-member ring formation at temperatures up to $2000 \mathrm{~K}$, but for very high temperatures of $2500 \mathrm{~K}$, the carbene route becomes the most important contributor. The formation of seven-member rings occurred within
\end{abstract}

\footnotetext{
${ }^{*}$ Corresponding author

Email address: mk306@cam.ac.uk (Markus Kraft)
}

Preprint submitted to Combustion and Flame

March 23, 2020 
$1 \mathrm{~ms}$ for all cases studied in the 0D reactors, suggesting that seven-member ring formation in PAHs containing a five-member ring is possible at flame temperatures.

Keywords: 7-member ring formation, density functional theory, Polyaromatic hydrocarbons, Bay closures

\section{Introduction}

Polycyclic aromatic hydrocarbons (PAHs) are carbonaceous molecules that form during the incomplete combustion of hydrocarbon fuels. They can also be thought of as hydrogen terminated graphene fragments that are ubiquitous in nature. They are also widely accepted to be the precursors to the formation of soot nanoparticles as well as fullerenes in combustion environments $[1,2,3,4]$. As a result, both PAHs and soot are known to be harmful to the environment, contributing to the warming of the atmosphere and melting of ice caps $[5,6,7]$, as well as soot being the second largest contributor to global warming after $\mathrm{CO}_{2}$ [8]. Soot and PAHs are also known to cause respiratory issues when inhaled $[9,10]$, making their emissions from combustion a public health concern as well. However, PAHs have also seen to play prominent roles in the chemistry occuring within interstellar dust $[11,12,13]$ as well as molecular electronics applications where a large variety of graphene nano-ribbons have been synthesised and had their electronic structure tuned [14]. As a result, numerous studies are present in the literature that study the formation and reaction pathways of PAHs. A large number of studies concern peri-condensed PAHs, whose delocalised $\pi$ network makes them the thermodynamically preferred structure type for aromatic hydrocarbons [15]. This includes growth pathways of PAHs, the most well known of which is via the hydrogen abstraction acetylene addition (HACA) mechanism proposed by Frenklach $[16,17,3]$. Other growth pathways exist, including addition by methyl radicals [18], addition by resonance-stabilized radical PAHs [19, 20, 21], the carbon-addition-hydrogen-migration (CAHM) pathway [22, 23], as well as DielsAlder type reactions [24].

Several studies have focused on the integration of curvature into graphenic PAHs, by focusing on the mechanisms by which a pentagonal or five-member ring could form. Such studies have included the five-member bay-capping reaction determined by You et al. [25], which was then used in a kinetic Monte Carlo (kMC) simulation to show curvature occurring during singular PAH growth [26]. The formation of curved PAHs has also been seen in kMC-molecular dynamics studies by Violi [27] as well as by Raj et al. [28] and Yapp et al. [29], where bay-capping and five-member ring migration reactions were seen to be key to curvature integration. Other pathways to fivemember ring formation and integration include those based on cyclodehydrogenation. 
This was studied computationally by density functional theory (DFT) calculations on various pathways including including hydrogen addition, hydrogen abstraction, and carbene formation, all followed by bay closures [30]. Recent work has also shown five-member ring addition can occur by reaction between an aryl radical and allenes [31]. The resulting curved PAHs have been seen to possess strong permanent dipole moments due to the flexoelectric effect which could have implications for their ability to interact with ions in flames $[32,33,34]$. Curved PAHs with five-member rings have also been seen to be more reactive with regards to both oxidation $[35,36]$ and recently growth by HACA [35, 37].

However, less focus has been given to PAHs containing seven-member rings. Whilst five-member ring PAHs result in bowl shaped structures with positive Gaussian curvature, seven-member ring PAHs result in saddle-shaped structures that have negative Gaussian curvature. Distored nano-graphenes containing seven-member rings have been synthesized by several methods [38, 39]. In addition, the formation of five-seven member ring defect pairs is key to forming closed fulleroid structures [40] and can occur by the Stone-Wales transformation [41, 42, 43], although these transformations are typically slow at flame conditions [44]. The formation of seven member rings by sequential HACA additions in small PAHs has also been considered by Kislov et al. [45]. In addition, it has been found that net negative curvature and hence seven-member ring formation is key to forming disordered 3D graphene sheets, a nanostructure key to seval carbon materials such as charcoal and activated carbon [46]. In particular, Martin et al. [46] found that chains of alternating five-member and seven-member rings resulted in line dislocations between the six-member rings of graphene, and this was required for the 3D graphene nanostructure to form. NMR studies on nanoporous carbons for a variety of applications such as batteries and supercapacitors have also shown that these carbons contain curved domains with both five and seven member rings [47, 48]. Seven-member ring formation has also been seen in tight-binding molecular dynamics studies of benzene combustion and soot particles at higher temperatures, as well as in molecular dynamics studies of trace-metal assisted soot formation $[49,50,51]$. Ricca et al. [52] also computed the infrared spectra of PAHs with five-seven member ring pairs and found that the PAH spectra is shifted due to this defect and could be important for class A astronomical spectra.

Formation of seven-member rings and coupled five-seven-member pairs in PAHs is therefore of interest for carbon nanomaterials in a variety of fields but kinetic studies of how this could occur are sparse. Therefore, the purpose of this paper is to computationally explore the possibility of seven-member ring formation by a variety of mechanisms considered previously for five and six member ring formation in 
PAHs by means of density functional theory and transition state theory calculations. Kinetic simulations in a 0D reactor at concentrations of species typical in flames and a variety of temperatures are then performed to see which routes are more important and how likely seven-member ring formation could be under flame conditions.

\section{Methodology}

In this work, seven-member ring formation was considered to occur in two overrarching categories. The first is by the HACA mechanism which underpins PAH growth and has been shown to be key to integrating five-member rings into flat PAH systems $[16,3,37]$. This was studied for two PAHs, A and B seen in Fig. 1. In both cases, the seven-member ring is formed by the HACA process acting on a bay site next to a five-member ring. PAH B also contains an odd-number of carbon atoms, making it a resonance-stabilized-radical (RSR) PAH, which has recently been suggested as potential precursors for soot nanoparticle formation in flames [53]. A jump process illustration of the formation of seven-member rings by HACA are seen in Fig. 2. The second category of seven-member ring formation studied in this work is by bay closure reactions. This was also studied for two PAHs, C and D also seen in Fig. 1, with the required seven-member bay again adjacent to a five-member ring. PAHs containing sites similar to these have also recently been observed in early soot imaged by high resolution atomic force microscopy [54], so studying the kinetics of seven-member ring formation could be of interest in soot as well. 
A<smiles>[R1]c1ccc2ccc3cccc4c5cccc6c(cccc6c1c2c34)cc5</smiles>

C<smiles>[R]=CC1=CC=c2ccc3ccc4ccccc4c3c2=c2c1ccc1cccc3c2=c13</smiles>

B<smiles>[R7]c1ccc2cc3ccc4cccc5c6cccc1c6c-2c3c45</smiles>

$\mathrm{D}$<smiles>[R20]c1ccc2ccc3cc4ccc5ccccc5c4c4c5ccccc5c1c2c34</smiles>

Figure 1: The starting PAH reactants which can integrate seven-member rings studied in this work. PAHs A and B can form a seven-member ring by the HACA mechanism. PAHs C and D can form a seven-member ring by bay closure reactions.

\section{Formation of R7 on PAH A}

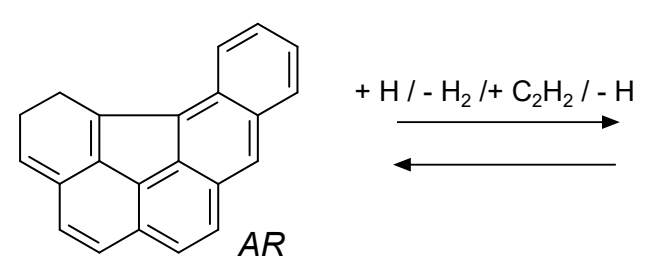<smiles>[In]c1cc2ccc3ccc4ccc5cccc6cc1c1c-6c5c4c3c21</smiles>

Formation of R7 on PAH B

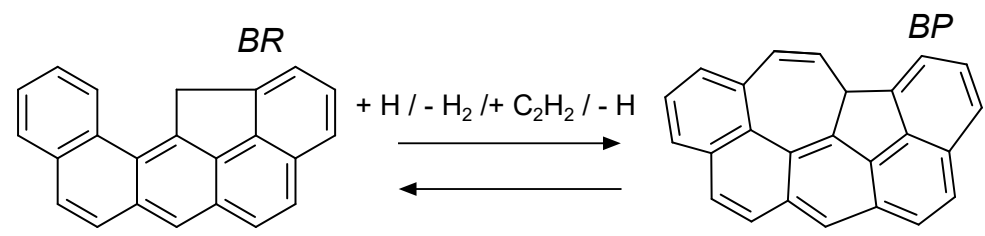

Figure 2: Jump process illustrating formation of seven-member ring by HACA acting on PAH A and $\mathrm{B}$.

There are four possible pathways by which the seven-member bay closure can 
occur. The first three involve an initial step, namely hydrogen abstraction, hydrogen addition, or formation of a carbene, followed by cyclisation and hydrogen loss to complete the bay closure. The fourth pathway involves the direct cyclisation occuring right away, followed by subsequent hydrogen loss. Jump process illustrations of these pathways are given in Fig. 3.

R7 formation by $\mathrm{H}$ Abstraction on PAH C

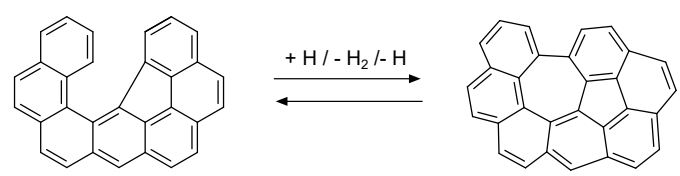

R7 formation by H Addition on PAH C

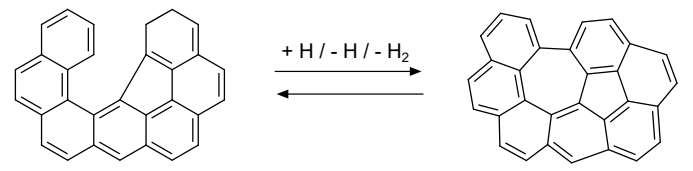

R7 formation by Direct Cyclization / Carbene formation on PAH C

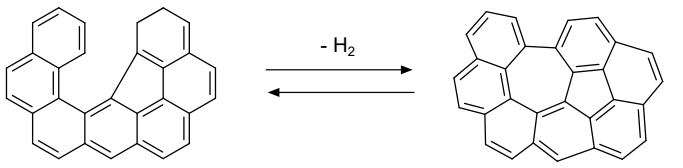

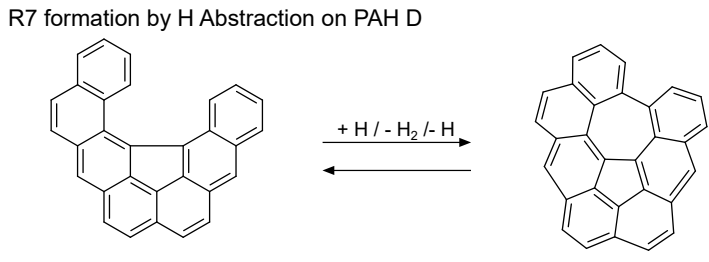

R7 formation by H Addition on PAH D
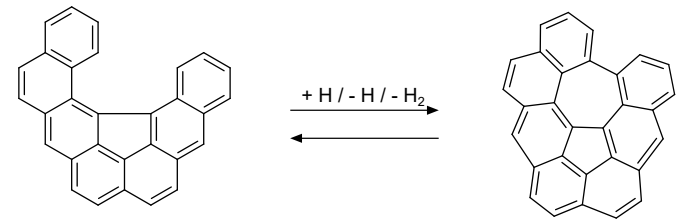

R7 formation by Direct Cyclization / Carbene formation on PAH D

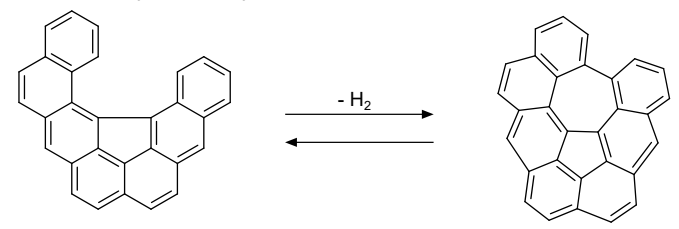

Figure 3: Jump process illustrating formation of seven-member ring by various bay closures in PAH C and D above.

The formation of a seven-member ring without an adjacent five-member ring has not been considered in this work. Nevertheless, the integration of five-seven-member ring pairs into graphenic substrates is a key line dislocation in the formation of 3D graphenic structures as well as fulleroids as mentioned previously [46]. All ten routes to seven-member ring formation were explored further computationally by means of density functional theory and rate constant calculations, followed by kinetic simulations performed at conditions relevant to flames. This is done in order to gain some insight on the likelihood of PAHs with seven-member rings forming in flames.

\subsection{Density Functional Theory calculations}

The potential energy surfaces of the HACA and bay closure reactions considered in this study were constructed by first performing geometry optimizations and frequency calculations at the B3LYP $/ 6-311+\mathrm{G}(\mathrm{d}, \mathrm{p})$ level of theory for all reactants, 
intermediates, transition states and products. The B3LYP functional has been shown to give reasonable geometries for systems concerning polycyclic aromatic hydrocarbons [30, 24]. For transition states, the vibrational frequencies were checked to ensure that only one imaginary frequency was present and that this vibrational mode corresponded to the reaction in question. In addition, since several studies have reported that B3LYP underpredicts the barrier heights of such organic reactions [55, 56], single point energies were also calculated for all species using the modern density functional M06-2X and with Dunning's cc-pVTZ basis set. This functional has been shown to give improved energy estimates for reactions involving hydrogen abstraction from various PAHs [56]. It is worth mentioning that PAH B is an RSR, and as such the pathways computed involve radical-radical reactions. Such reactions can require multireference methods, but due to the computational restrictions, the M06-2X functional was used for this pathway as well. It has also been previously shown that the M06-2X functional gives very good descriptions of the energetics of bond dissociation in which two radicals are produced. This was seen to be true for a variety of hydrocarbons and hydrocarbon derivatives, and hence the M06-2X functional is adopted in this work [57]. In general, the barriers predicted by B3LYP were lower compared to those of M06-2X, as expected. All density functional theory calculations were performed using the Gaussian 16 program suite [58].

\subsection{Computation of rate constants}

The energetics and molecular properties computed by the DFT calculations were then used for the rate constant calculations. Rate constants were determined by means of canonical transition state theory as implemented in the Arkane package within the Reaction Mechanism Generator (RMG) software [59]. Transition state theory was used as the reactions studied in this work have appreciable barriers, and so more sophisticated methods such as variational transition state theory were not used in this work. Nevertheless, it is likely that the rates reported here will be an overestimate as a result. The rate constant is therefore given by the standard transition state expression:

$$
k=\frac{k_{B} T}{h} \frac{q^{\dagger}}{\prod_{i}^{n_{\text {reactants }}} q_{i}} \exp \left(\frac{-\Delta E_{0}}{R T}\right)
$$

where $k$ is the rate constant, $k_{B}$ is the Boltzmann constant, $T$ is temperature, $h$ is Planck's constant, $q$ is the total partition function, and $\Delta E_{0}$ is the classical barrier height. The partition functions for all speciues were computed using the Rigid-Rotor, Harmonic-Oscillator (RRHO) model. To account for quantum tunneling effects, the 
simple Wigner correction was employed [60], giving the tunnelling correction factor, $C_{W}$ as follows:

$$
C_{W}=1-\frac{1}{24}\left(\frac{h \nu^{\dagger}}{k_{B} T}\right)^{2}
$$

with $\nu^{\dagger}$ being the magnitude of the imaginary frequency of the transition state. The Eckart tunneling correction is also commonly used [61], but the difference between the Eckart and Wigner correction in this case was negligible. In the temperature range used for the $0 \mathrm{D}$ reactor simulations, the tunneling factors are between 1.03 at $1000 \mathrm{~K}$ and 1.01 at $2500 \mathrm{~K}$ for both Eckart and Wigner tunneling corrections. The rate constants were computed at a range of temperatures $(200 \mathrm{~K}$ to $3000 \mathrm{~K})$ and then fitted to the modified Arrhenius expression, again as implemented in Arkane:

$$
k=A\left(\frac{T}{T_{0}}\right)^{n} \exp \left(\frac{-E_{A}}{R T}\right)
$$

In all the rate constants here, $T_{0}$ was taken as $1 \mathrm{~K}$ and was effectively removed from the fitting. Even though the reaction pathways studied in this work contain several unimolecular reactions, pressure dependence was not considered. Generally, pressure dependence is less likely for for larger species, such as the PAHs studied here as there are several more modes available for the randomization of the internal energy from collisions. To check this, pressure-dependent rate constants were computed for the main unimolecular reactions in the HACA pathway for PAH A, including the bay closures in $\mathrm{AS} 2 \mathrm{a}$ and $\mathrm{AS} 2 \mathrm{~b}$ to form AS3a and AS3b as well as hydrogen loss from AS3a and AS3b to form product AP. RRKM theory as implemented in KiSThelp [62] was used for the calculations, with nitrogen as the bath gas and collisional parameters of PAHs estimated based on their molecular weight using the results of Wang and Frenklach [63]. The calculations suggested that these unimolecular reactions are weakly pressure dependent. For the bay closures of AS2a and AS2b, the closure rate constants are at $96 \%$ and $99 \%$ of their high pressure limits at $1500 \mathrm{~K}$ and 1 bar. The rate constants of hydrogen losses from AS3a and AS3b are at 32\% and $47 \%$ of their high pressure limits at $1500 \mathrm{~K}$ and 1 bar. A more detailed description of the RRKM calculations and plots of pressure dependence may be found in the supplemental information. As such, pressure dependence was not considered further in this work.

\subsection{Kinetic simulations}

The rate constants provide a first estimate on the time scale required for the formation of seven-membered rings in the presence of combustion species. However, 
the different reaction pathways affecting a starting site compete with each other making it difficult to determine the likeliness of each one. To estimate the conditions under which pathway is favoured, a set of kinetic simulations in a 0D isothermal reactor model were used. The simulations were performed using both the B3LYP $/ 6$ $311 \mathrm{G}+(\mathrm{d}, \mathrm{p})$ and the M06-2X/cc-pVTZ levels of theory. For each case a reaction time of $100 \mathrm{~ms}$ was used under a pressure of $1 \mathrm{~atm}$ and temperatures of 1000, 1500, 2000 , and $2500 \mathrm{~K}$. The mole fractions for all cases were assumed to be $10^{-5}$ for the starting PAH, $10^{-3} \mathrm{H}, 0.1 \mathrm{H}_{2}, 0.1 \mathrm{C}_{2} \mathrm{H}_{2}$ and the rest of $\mathrm{N}_{2}$ which resemble typical flame conditions. Using an identical mole fraction of the starting PAH allows a straightforward comparison of the time required for each studied reaction to happen and the net rates of formation for the seven-member ring containing curved products.

\section{Results and Discussion}

\subsection{Potential Energy Surfaces}

The potential energy surfaces computed at the B3LYP $/ 6-311+\mathrm{G}(\mathrm{d}, \mathrm{p})$ were constructed for all ten pathways. Optimized geometries at this level of theory are also shown for all species in each pathway. The energies computed using the single point energy calculations at the M06-2X/cc-pVTZ level of theory are shown in parentheses and in red.

Every species and transition state is given a name shown in italics next to the structure in the potential energy surface figures. The naming convention is as follows: The first capital letter refers to the initial PAH (A,B,C or D). This is followed by either $\mathrm{S}$ for species or TS for transition state. The next number refers to which intermediate or transition state it is along the pathway, and the final lowercase letter refers to the type of pathway and route, as in most cases there are two routes for each type of pathway (abstraction, addition, carbene formation, direct cyclisation). In this case, a and b are for hydrogen abstraction based routes, $\mathrm{c}$ and $\mathrm{d}$ are for hydrogen addition based routes, e and $\mathrm{f}$ are for carbene based routes, and $\mathrm{g}$ and $\mathrm{h}$ are for direct cyclisation routes. For simplicity, the PAH reactants and products are denoted by $\mathrm{AR}$ and $\mathrm{AP}, \mathrm{BR}$ and $\mathrm{BP}, \mathrm{CR}$ and $\mathrm{CP}$, and $\mathrm{DR}$ and $\mathrm{DP}$ as these structures are shared between multiple pathways. As an example, the first intermediates in PAH C forming a seven-member ring facilitated by hydrogen abstraction will have the names CS1a and CS1b for the two different routes.

In the subsequent discussions of the pathways, the M06-2X/cc-pVTZ energies are used as these were used for the computation of the rate constants in the kinetic simulations. Comparing the two levels of theory, it seems that B3LYP tends to predict lower barriers for hydrogen abstractions, with most abstractions in this work having 
barriers between $12-14 \mathrm{kcal} / \mathrm{mol}$ compared to $16-19 \mathrm{kcal} / \mathrm{mol}$ predicted by M06-2X. This agrees with previous findings for hydrogen abstractions [56]. Similarly, B3LYP tends to predict lower barriers for hydrogen addition and direct cyclisation processes in this work compared to M06-2X. However, for processes involving hydrogen migration or loss, B3LYP sometimes predicts slightly higher barrier than M06-2X. Nevertheless, it is observed that the barriers predicted by M06-2X and B3LYP are generally similar, as are the predicted trends. Comparison of the barrier heights computed at the M06-2X/cc-pVTZ level of theory for hydrogen abstraction by $\mathrm{H}$ atoms and acetylene addition in this work to those computed at the G3(MP2,CC) level of theory by [24] also shows reasonable agreement, with the G3 calculations suggesting abstraction barriers between $16-18 \mathrm{kcal} / \mathrm{mol}$, very similar to this work. The acetylene addition barriers in [24] are predicted to be between 2 and $6 \mathrm{kcal} / \mathrm{mol}$ compared to 4 to $8 \mathrm{kcal} / \mathrm{mol}$ in this work, again suggesting reasonable agreement.

\subsubsection{PAH A - HACA growth pathways $a$ and $b$}

Figure 4 presents the potential energy diagram for HACA growth on $\mathrm{PAH} A$ resulting in the formation of a seven-member ring adjacent to a five-member ring, or a 7-5 ring pair. The first step in this process is hydrogen abstraction from one of the two edge carbons in the bay site next to the five-member ring, resulting in a radical site. The barriers for the two abstractions are very similar, at 18.4 and $17.3 \mathrm{kcal} / \mathrm{mol}$ for the sites using M06-2X. The two radicals AS1a and AS1b can interconvert by hydrogen migration, as indicated by the $\mathbb{\sharp}$. This is described further in section 3.1.11 for all PAHs, as the transitions states for this have higher relative energies. The next step involves acetylene $\left(\mathrm{C}_{2} \mathrm{H}_{2}\right)$ addition to the formed radical site. Again the addition step has very similar and rather low barriers for the two routes, requiring 5.8 and 4.7 $\mathrm{kcal} / \mathrm{mol}$. From here, AS2a and AS2b, three sub-pathways are possible. For the first sub-pathway, the last two steps are seen to have significantly higher barriers than the first two. The cyclisations have barriers of 26.0 and $31.2 \mathrm{kcal} / \mathrm{mol}$, followed by hydrogen loss with barriers of 27.4 and $29.1 \mathrm{kcal} / \mathrm{mol}$ to complete the seven-member ring formation. The overall formation process is exothermic, releasing $33.2 \mathrm{kcal} / \mathrm{mol}$, and little difference is seen between the two routes. An alternative route to achieve the bay closure is presented in Figure 5. Here, the hydrogen migrates towards the acetylene from the $\mathrm{PAH}$, requiring larger barriers of 27 and $33.5 \mathrm{kcal} / \mathrm{mol}$ for the two pathways. The subsequent cyclisations have very low barriers of 4.5 and 2.5 $\mathrm{kcal} / \mathrm{mol}$, but in both cases the final hydrogen loss requires overcoming a much larger barrier of 45.7 and $45.5 \mathrm{kcal} / \mathrm{mol}$, which would suggest this pathway is less preferable. Formation of ethynyl-substituded side products ASPa and ASPb is also possible by hydrogen loss from $\mathrm{AS} 2 \mathrm{a}$ and $\mathrm{AS} 2 \mathrm{~b}$, and is shown in Figure 6. This 
hydrogen loss does have a large barrier of 41.1 and $41.5 \mathrm{kcal} / \mathrm{mol}$ for the two cases, but is a one step process.

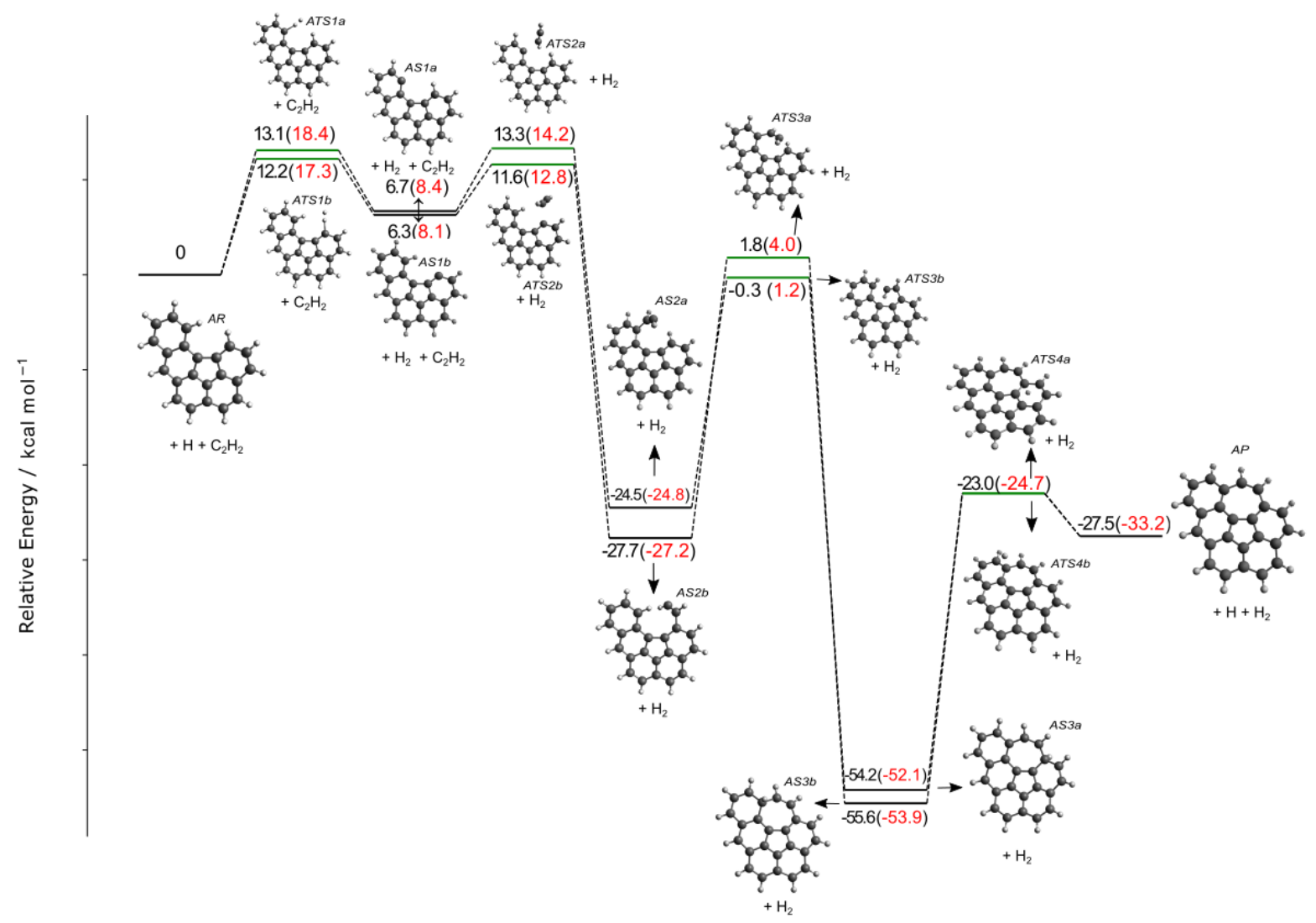

Figure 4: Potential Energy surface for the formation of a seven-member ring by HACA on PAH A at $0 \mathrm{~K}$. The relative energy of the different species are computed at both the M06-2X/cc-pVTZ and B3LYP $/ 6-311+\mathrm{G}(\mathrm{d}, \mathrm{p})$ level of theory. 


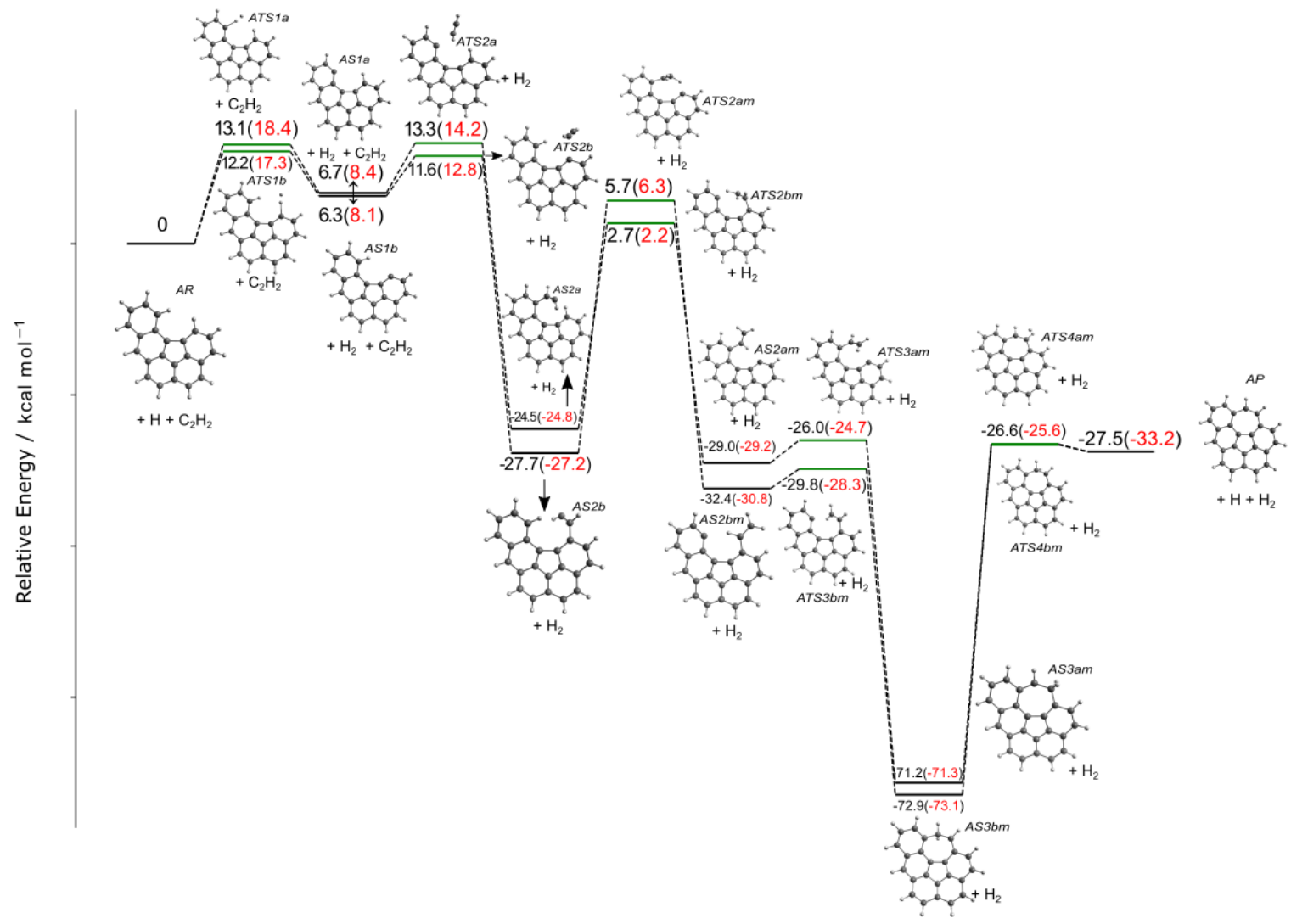

Figure 5: Potential Energy surface for the formation of a seven-member ring by HACA followed by hydrogen migration to the acetylene group on $\mathrm{PAH} \mathrm{A}$ at $0 \mathrm{~K}$. The relative energy of the different species are computed at both the M06-2X/cc-pVTZ and B3LYP/6-311+G(d,p) level of theory. 


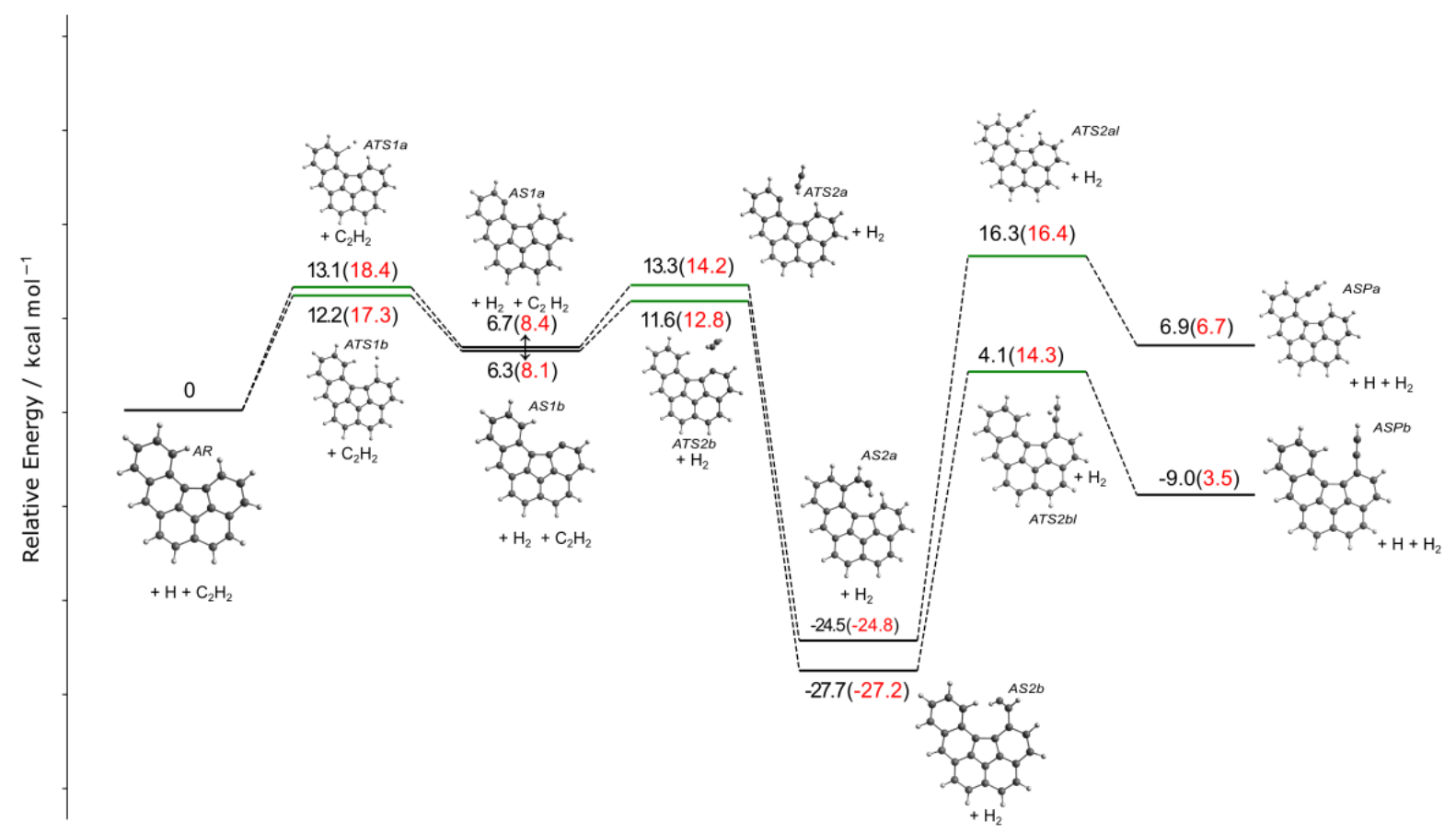

Figure 6: Potential Energy surface for the formation of ethynyl-substituted products by HACA on PAH A at $0 \mathrm{~K}$. The relative energy of the different species are computed at both the M06-2X/ccpVTZ and B3LYP $/ 6-311+\mathrm{G}(\mathrm{d}, \mathrm{p})$ level of theory.

\subsection{2. $P A H B-H A C A$ growth pathways $a$ and $b$}

Figure 7 presents the potential energy diagram for HACA growth on PAH B. The required steps are the same as for PAH A: hydrogen abstraction followed by acetylene addition, ring cyclisation, and then hydrogen loss to finish the process. However, of note here is that PAH B contains an odd number of carbon atoms and is a RSR PAH and provides a point of comparison to PAH A, a closed-shell species. As with PAH A, there are two carbons on which the the initial hydrogen abstraction may occur, either next to the five-member or 6-member ring, resulting in two routes. This first abstraction step again has very similar barriers of 16 and $18.6 \mathrm{kcal} / \mathrm{mol}$ for the two routes, and are also similar to the hydrogen abstraction step for PAH A. The barriers predicted by M06-2X are also slightly higher than those by B3LYP, which is consistent with PAH A. In both abstraction cases, the resulting radical is a triplet, which was found to have lower energy than the singlet state. Additionally, the triplet state remains energetically favoured over the singlet throughout all the pathways for $\mathrm{PAH} \mathrm{B}$ in this case, and no inter-crossing was predicted by the single-reference DFT method in this work. However, unlike PAH A, the two acetylene addition steps have 
quite different barriers of $8.5 \mathrm{kcal} / \mathrm{mol}$ and $4.7 \mathrm{kcal} / \mathrm{mol}$, with acetylene addition next to the five-member ring being more difficult. The difference is even more significant for the cyclisation, with the barrier for the cyclisation adjacent to the five-member ring being $20.3 \mathrm{kcal} / \mathrm{mol}$ whilst it is only $3.2 \mathrm{kcal} / \mathrm{mol}$ for the cyclisation next to the 6 -member ring route. Nevertheless, the cyclisation appears to be substantially easier for PAH B than PAH A in both cases. The hydrogen loss steps have higher barriers for both routes being 30.9 and $23.5 \mathrm{kcal} / \mathrm{mol}$. These barriers are also very similar to the hydrogen loss barriers for PAH A. For both PAH A and PAH B the hydrogen loss has the largest barrier. Again, the overall formation process for the seven-member ring is exothermic, releasing $45.3 \mathrm{kcal} / \mathrm{mol}$ in this case. As with PAH A, PAH B can undergo bay closure by the hydrogen migrating to the acetylene from the adjacent site on the PAH before cyclisation occurs. In this case, the migration barriers for the two routes are significantly lower that PAH A at $12.9 \mathrm{kcal} / \mathrm{mol}$ and $20.7 \mathrm{kcal} / \mathrm{mol}$ respectively. The cyclisation barriers are higher than PAH A at 4.9 and $6.5 \mathrm{kcal} / \mathrm{mol}$, but the final hydrogen loss is again substantially easier than PAH A at 28.9 and 30.9 $\mathrm{kcal} / \mathrm{mol}$, which would suggest this pathway may be more important than for PAH A. PAH B can also form various side products. Hydrogen loss from BS2a and BS2b produce ethynyl-substituted PAHs like with $\mathrm{PAH}$ A, but this requires overcoming a high barrier of $38.4 \mathrm{kcal} / \mathrm{mol}$. BS2b can also undergo a direct ring-enlargement by which the five-member ring is converted into a seven-member ring [64]. The first step involves the acetylene bonding to the five-member ring to create a four-member ring, with a barrier of $25 \mathrm{kcal} / \mathrm{mol}$. The adjacent four-member and five-member rings then fuse to create a seven-member ring, with a moderate barrier of $13.2 \mathrm{kcal} / \mathrm{mol}$. This results in a product with a seven-member ring as well, but noticeably not adjacent to a five-member ring. 


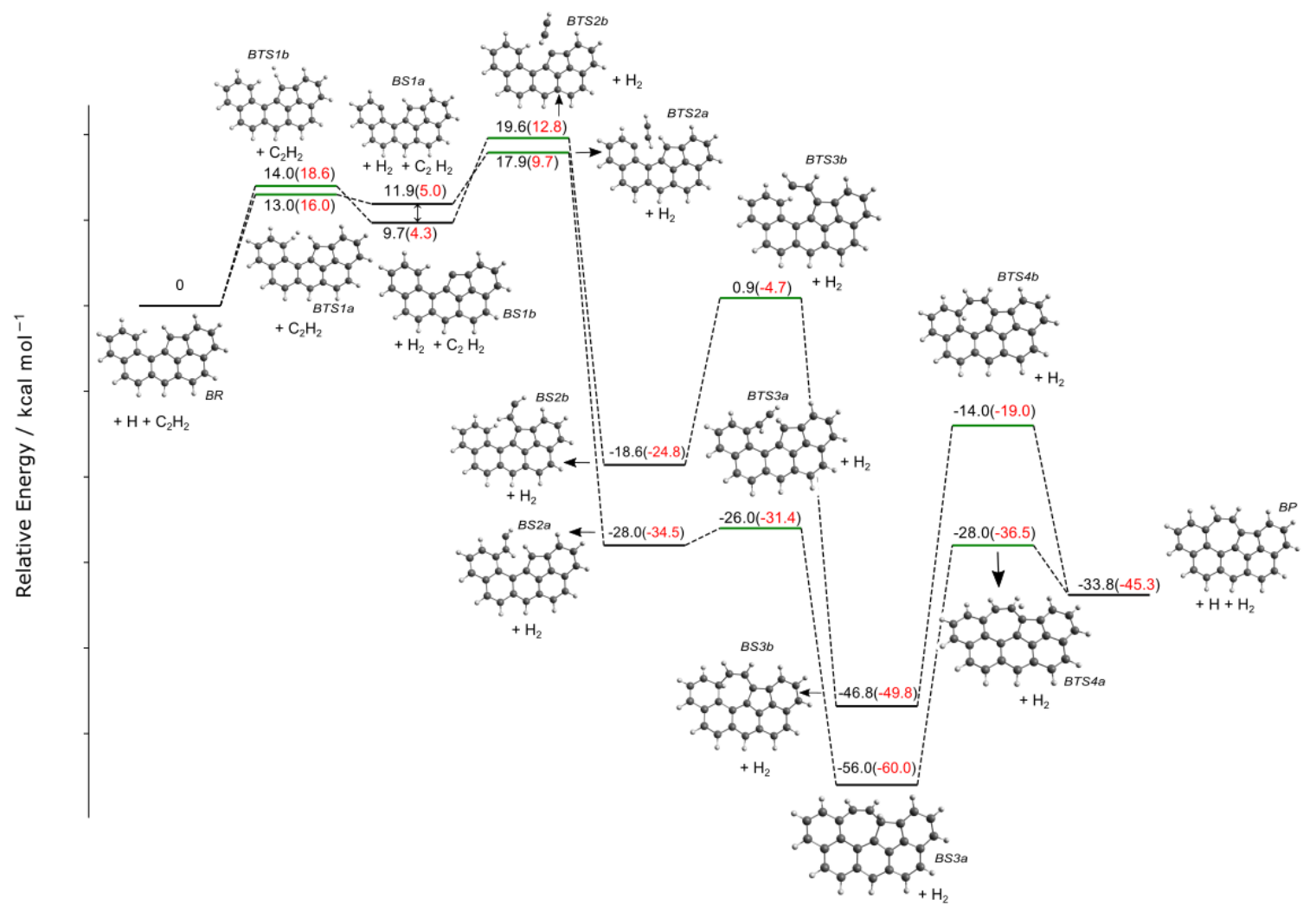

Figure 7: Potential Energy surface for the formation of a seven-member ring by HACA on PAH B at $0 \mathrm{~K}$. The relative energy of the different species are computed at both the M06-2X/cc-pVTZ and B3LYP $/ 6-311+\mathrm{G}(\mathrm{d}, \mathrm{p})$ level of theory. 


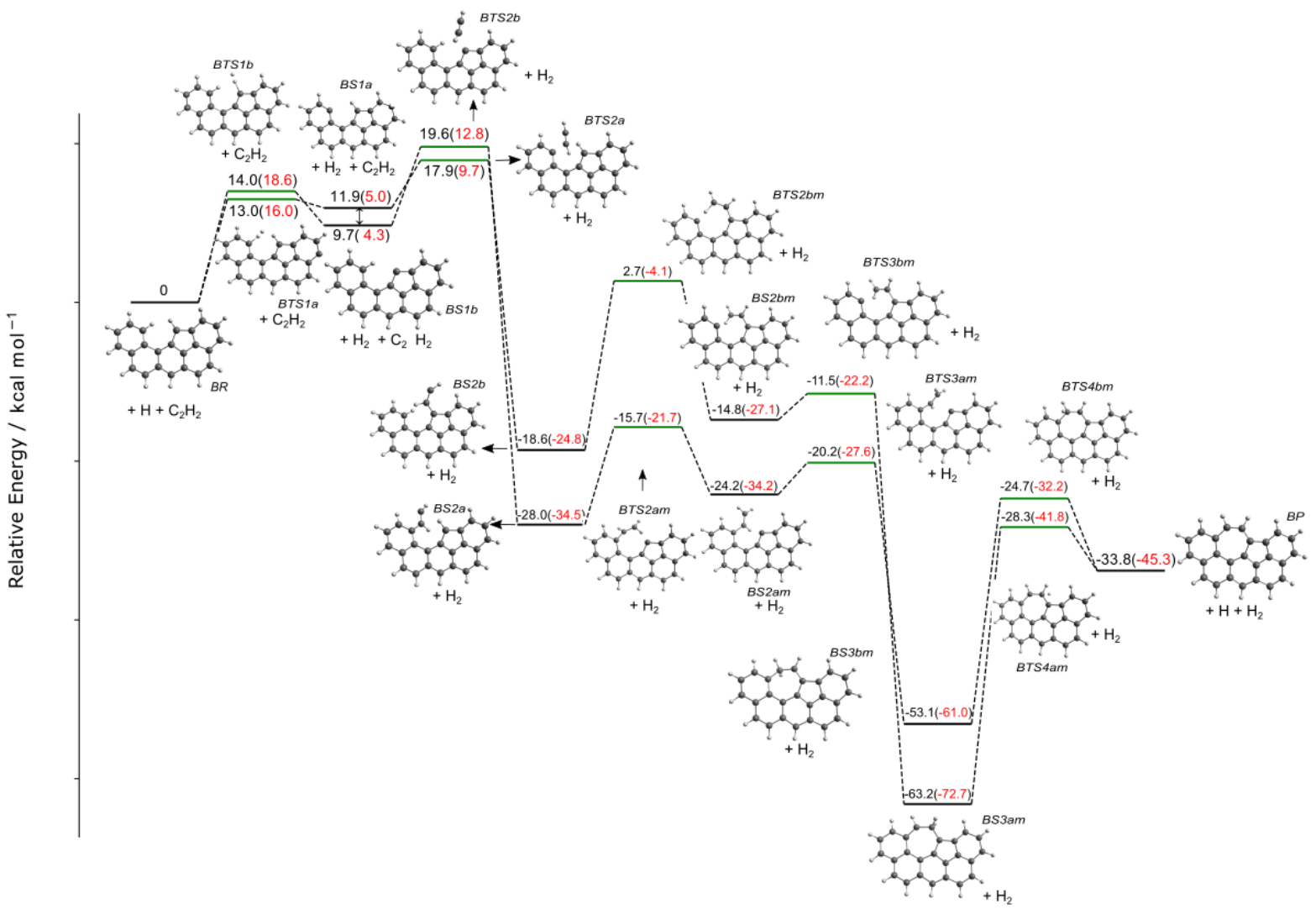

Figure 8: Potential Energy surface for the formation of a seven-member ring by HACA followed by hydrogen migration to the acetylene group on $\mathrm{PAH} \mathrm{B}$ at $0 \mathrm{~K}$. The relative energy of the different species are computed at both the M06-2X/cc-pVTZ and B3LYP/6-311 $+\mathrm{G}(\mathrm{d}, \mathrm{p})$ level of theory. 


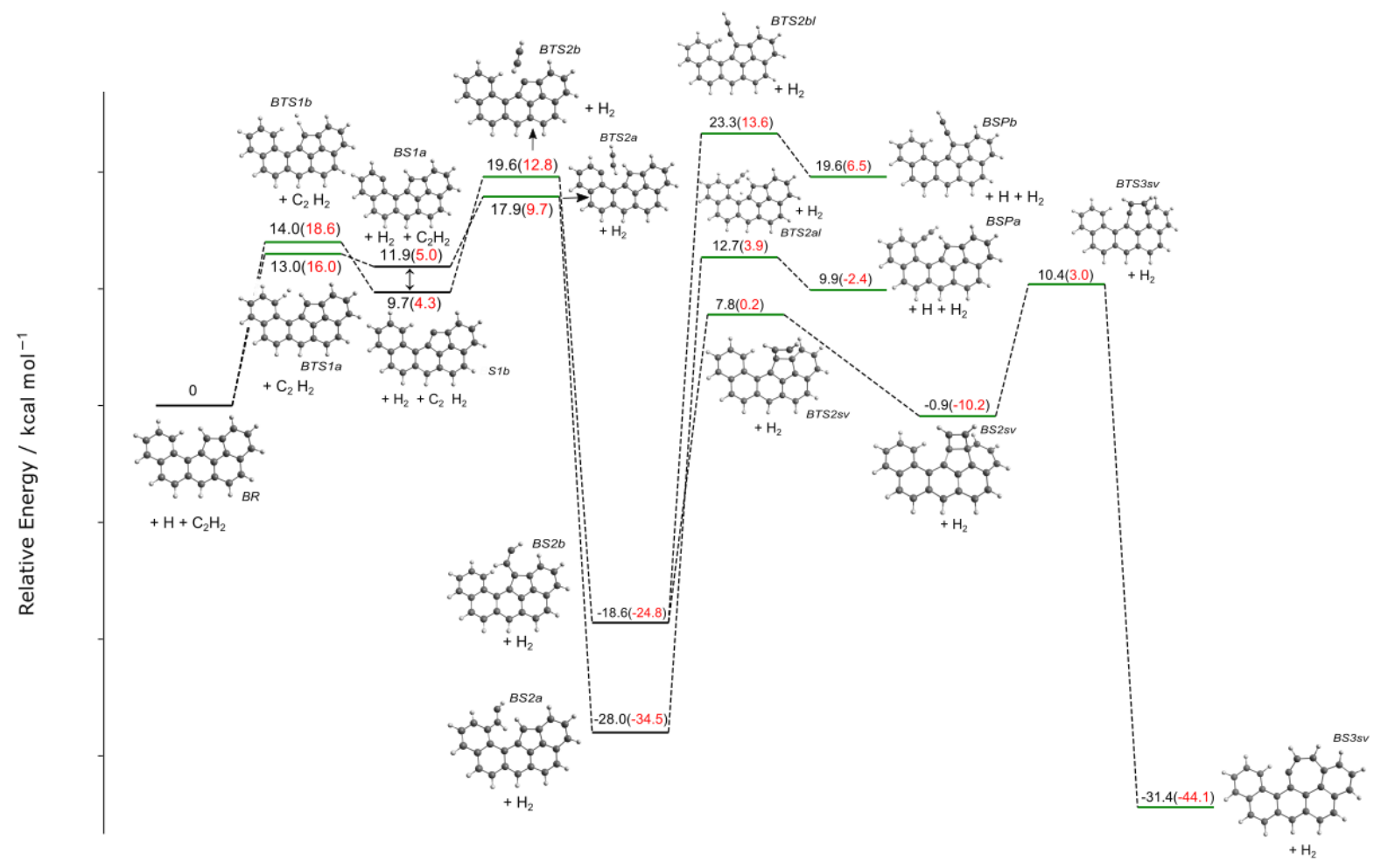

Figure 9: Potential Energy surface for the formation of byproducts of HACA on PAH B at 0 $\mathrm{K}$. The relative energy of the different species are computed at both the M06-2X/cc-pVTZ and B3LYP $/ 6-311+\mathrm{G}(\mathrm{d}, \mathrm{p})$ level of theory.

\subsubsection{PAH B - Rearrangement of five-seven-member ring pair to hexagons}

The product of the HACA process on PAH B, BP is able to have its five-seven member ring pair converted to a six-six member ring pair through a similar mechanism by which azulene is converted to naphthalene as described by [65]. This is presented in Figure 10. First, hydrogen addition occurs on the seven-member ring, with a small barrier of $3.6 \mathrm{kcal} / \mathrm{mol}$. This hydrogen then migrates to the five-memberseven-member ring edge, which requires a large barrier of $41.1 \mathrm{kcal} / \mathrm{mol}$ and is by far the highest barrier in this pathway. From there, the five-seven member ring pair is converted into a six-member ring and five-member ring partitioned by a triangular structure, with a barrier of $9.3 \mathrm{kcal} / \mathrm{mol}$. The five-member ring and triangle then fuse to form the second six-member ring, with a very low barrier of $3.8 \mathrm{kcal} / \mathrm{mol}$, and being nearly $30 \mathrm{kcal} / \mathrm{mol}$ downhill. Finally, the hydrogen is ejected with a barrier of $16 \mathrm{kcal} / \mathrm{mol}$. It is worth noting that a similar rearrangement is not possible with 
the other products AP, CP, or DP, because the five-seven member pairs in these structures are enclosed by more six-member rings.

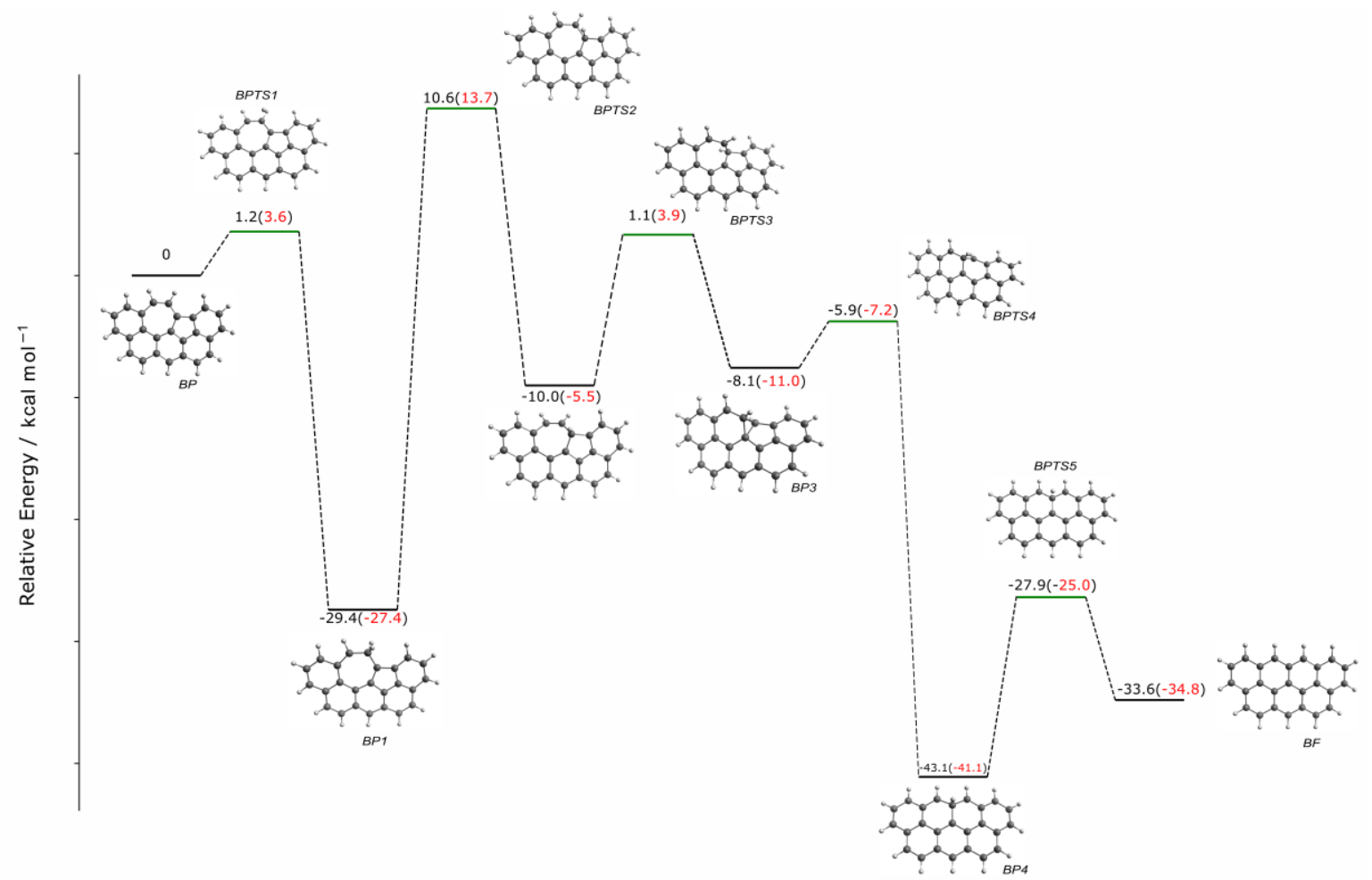

Figure 10: Potential Energy surface for the formation of byproducts of HACA on PAH B at 0 $\mathrm{K}$. The relative energy of the different species are computed at both the M06-2X/cc-pVTZ and B3LYP $/ 6-311+\mathrm{G}(\mathrm{d}, \mathrm{p})$ level of theory.

\subsection{4. $P A H C$ - H-abstraction facilitated bay closure pathways $a$ and $b$}

Figure 11 presents the potential energy diagram for $\mathrm{H}$ abstraction facilitated seven-member ring bay closure in PAH C. This pathway consists of three steps: $\mathrm{H}$ abstraction followed by cyclisation and finally hydrogen loss to complete the closure. The barrier for the abstraction step is nearly identical for both potential sites, at 17.3 and $17.6 \mathrm{kcal} / \mathrm{mol}$. This value is very similar to hydrogen abstractions from PAHs a and $\mathrm{b}$ as well. The cyclisation steps have substantially different barriers of 7.0 and $13.1 \mathrm{kcal} / \mathrm{mol}$, with the cyclisation being easier when the initial abstraction occurs on the ring adjacent to the five-member ring. The hydrogen loss step has similar barriers, being 31.9 and $29.7 \mathrm{kcal} / \mathrm{mol}$. This is once again the step with the highest barrier and also has barriers similar to those seen for hydrogen losses from PAHs a 
and b. However, the overall process for the bay closure is endothermic requiring 10.1 $\mathrm{kcal} / \mathrm{mol}$ in this case compared to the exothermicity of the HACA routes.

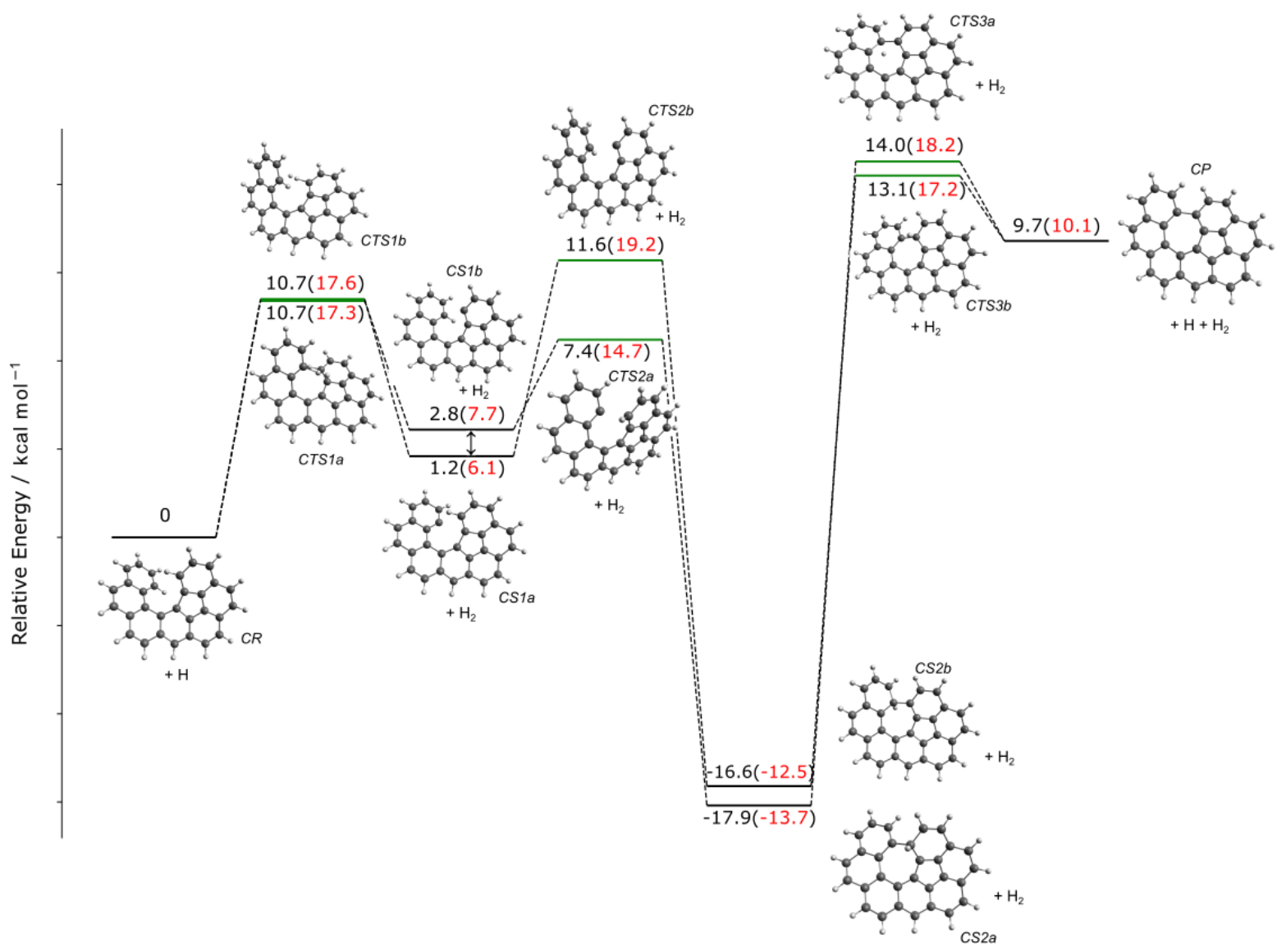

Figure 11: Potential Energy surface for the formation of a seven-member ring by hydrogen abstraction (pathways a and b) followed by cyclisation and bay closure in PAH C at $0 \mathrm{~K}$. The relative energy of the different species are computed at both the M06-2X/cc-pVTZ and B3LYP/6-311+G(d,p) level of theory.

\subsubsection{PAH $C$ - H-addition facilitated bay closure pathways $c$ and $d$}

Figure 12 presents the potential energy diagram for $\mathrm{H}$ addition facilitated sevenmember ring bay closure in PAH C. The steps in this pathway consists of hydrogen addition to the carbon atom, cyclisation, loss of a hydrogen atom, further loss of two hydrogen atoms as $\mathrm{H}_{2}$, and finally hydrogen migration to complete the closure. The initial hydrogen addition step requires low barriers for both sites, at 6.6 and $5.7 \mathrm{kcal} / \mathrm{mol}$. The B3LYP barriers in this case are lower, at 2.2 and $2.6 \mathrm{kcal} / \mathrm{mol}$, 
suggesting that hydrogen addition predictions are underestimated like those those for hydrogen abstraction. The cyclisation step has quite different barriers of 18.3 and and $33.6 \mathrm{kcal} / \mathrm{mol}$. This results in a high energy and low energy route, with the high energy route starting with hydrogen addition to the carbon nearer the five-member ring. The hydrogen loss steps have similar barriers of 35.4 and $35.9 \mathrm{kcal} / \mathrm{mol}$ for the two routes, which is similar to hydrogen losses seen for previous processes. The $\mathrm{H}_{2}$ loss step has by far the highest barriers for both routes. The barrier is for the low energy route is actually higher in this case, at $102.3 \mathrm{kcal} / \mathrm{mol}$ compared to 88.8 $\mathrm{kcal} / \mathrm{mol}$ for the higher energy route. The final hydrogen migration has a very low barrier, being $4.1 \mathrm{kcal} / \mathrm{mol}$ for the high energy route and $5.0 \mathrm{kcal} / \mathrm{mol}$ for the low energy route. Clearly, the feasibility of this route is limited by the very large barriers required to overcome for the $\mathrm{H}_{2}$ loss. 


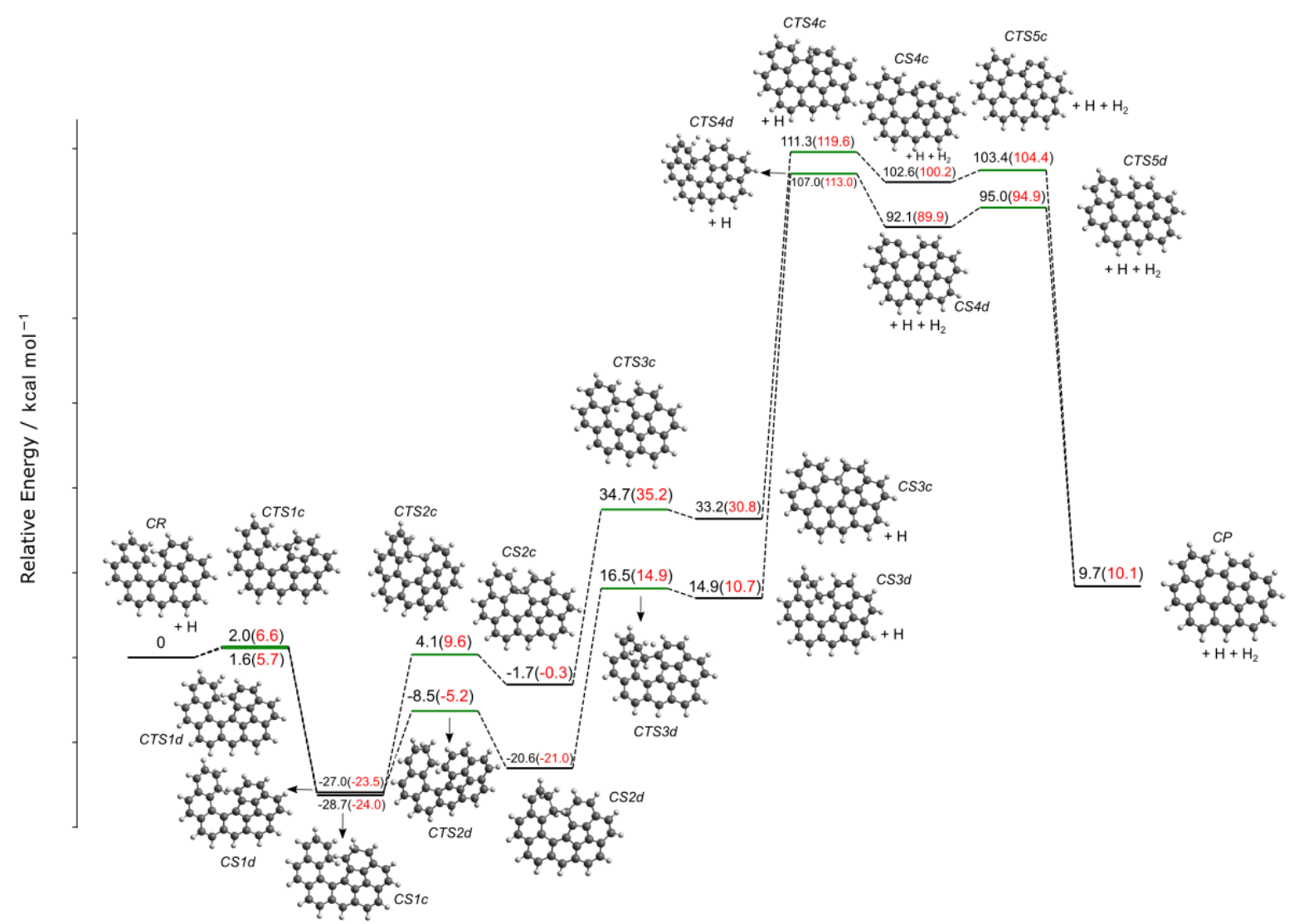

Figure 12: Potential Energy surface for the formation of a seven-member ring by hydrogen addition (pathways c and d) followed by cyclisation and bay closure in PAH C at $0 \mathrm{~K}$. The relative energy of the different species are computed at both the M06-2X/cc-pVTZ and B3LYP/6-311+G(d,p) level of theory.

\subsubsection{PAH C - Carbene facilitated bay closure pathways $e$ and $f$}

Figure 13 presents the potential energy diagram from carbene formation facilitated seven-member ring bay closure in PAH C. The steps in this pathway consists of carbene formation by hydrogen migration from the bay, cyclisation, several hydrogen migrations, and then finally the loss of two hydrogen atoms as $\mathrm{H}_{2}$. The initial hydrogen migration step requires very high barriers for both potential carbenes, at 84.5 and $96.1 \mathrm{kcal} / \mathrm{mol}$. The subsequent bay closures both have low barriers of 8.6 and $3.6 \mathrm{kcal} / \mathrm{mol}$. However, the resulting structures after the bay closures are quite different, with one structure forming a triangle connecting two 6-member rings at a much lower energy and the other forming the heptagon directly with a much higher energy. In the path where the heptagon forms immediately, two hydrogen migrations 
are required for the hydrogen to get into position to undergo $\mathrm{H}_{2}$ loss with hydrogen on the carbene site. These have a low barrier of $3.7 \mathrm{kcal} / \mathrm{mol}$ followed by a more difficult migration with $32.2 \mathrm{kcal} / \mathrm{mol}$. The final $\mathrm{H}_{2}$ loss step has a very large barrier of $98.1 \mathrm{kcal} / \mathrm{mol}$, similar to the barriers seen for $\mathrm{H}_{2}$ loss in the hydrogen addition pathway. In the other path, a hydrogen migration is required to break the triangle and form the heptagon after the cyclisation, which requires a quite large barrier of $64.0 \mathrm{kcal} / \mathrm{mol}$ compared to the hydrogen migrations in the other path. However, the final $\mathrm{H}_{2}$ loss in this pathway is much easier, requiring a moderate barrier of 28.5 $\mathrm{kcal} / \mathrm{mol}$. This may be the case as the $\mathrm{H}_{2}$ loss occurs across an armchair site as opposed to a free edge in the first pathway.

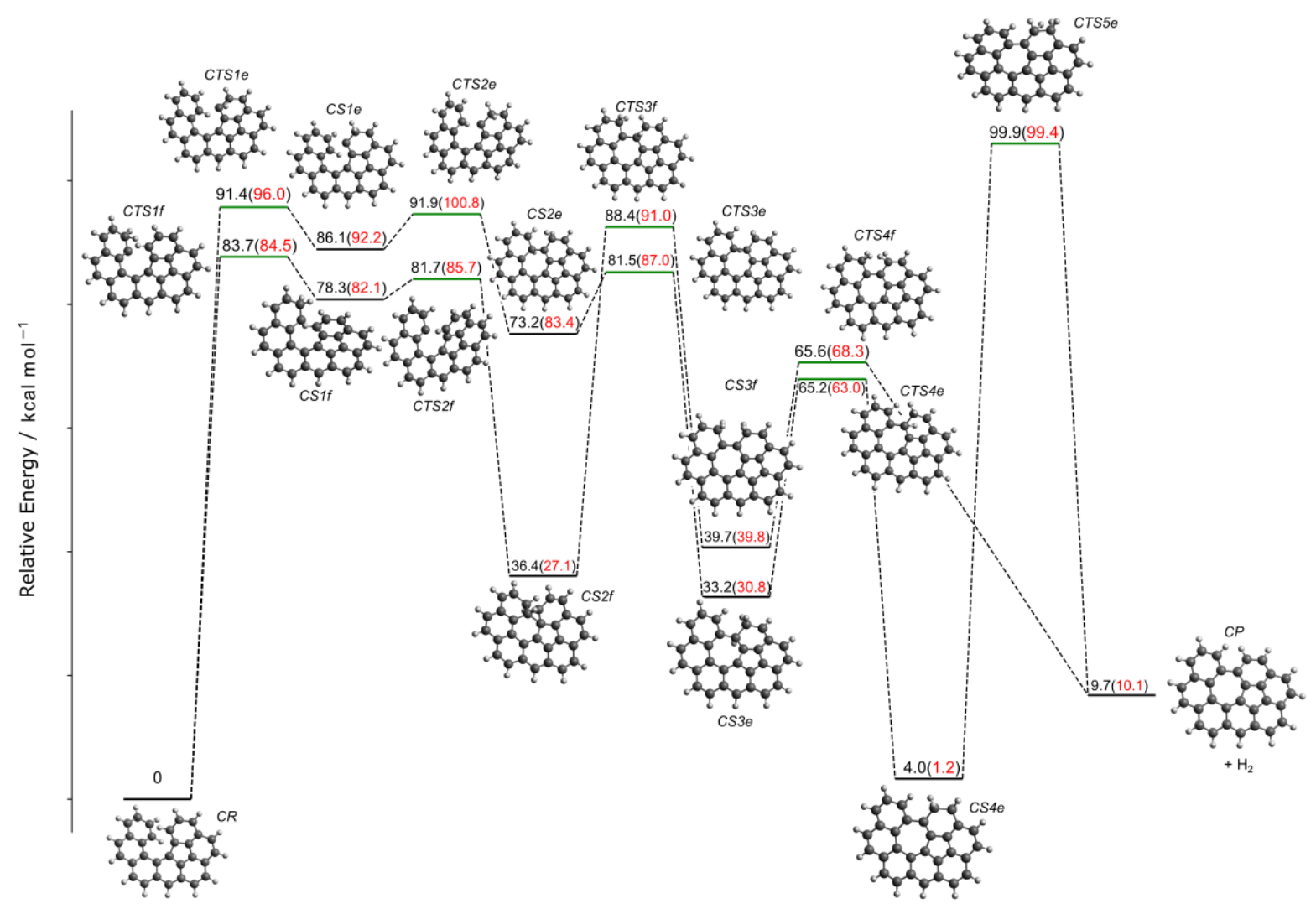

Figure 13: Potential Energy surface for the formation of a seven-member ring by carbene formation (pathways e and $\mathrm{f}$ ) followed by cyclisation and bay closure in PAH C at $0 \mathrm{~K}$. The relative energy of the different species are computed at both the M06-2X/cc-pVTZ and B3LYP/6-311+G(d,p) level of theory. 


\subsubsection{PAH C - Direct cyclisation bay closure pathway $g$}

Figure 14 presents the potential energy diagram for direct cyclisation sevenmember ring bay closure in PAH C. This is by far this simplest pathway, requiring only a cyclisation followed by $\mathrm{H}_{2}$ loss. The initial cyclisation has a very large barrier of $101.7 \mathrm{kcal} / \mathrm{mol}$, which is understandable as there is no aromatic stability to drive the bay to close as there would be with a 6 -member bay closure [66]. The cyclisation could only happen in the cis-orientation in this case as the trans structure was found to be unstable. The $\mathrm{H}_{2}$ loss has a moderate barrier of $20.7 \mathrm{kcal} / \mathrm{mol}$, which again occurs in an armchair site and is similar to the armchair hydrogen loss seen in the carbene route for PAH C.

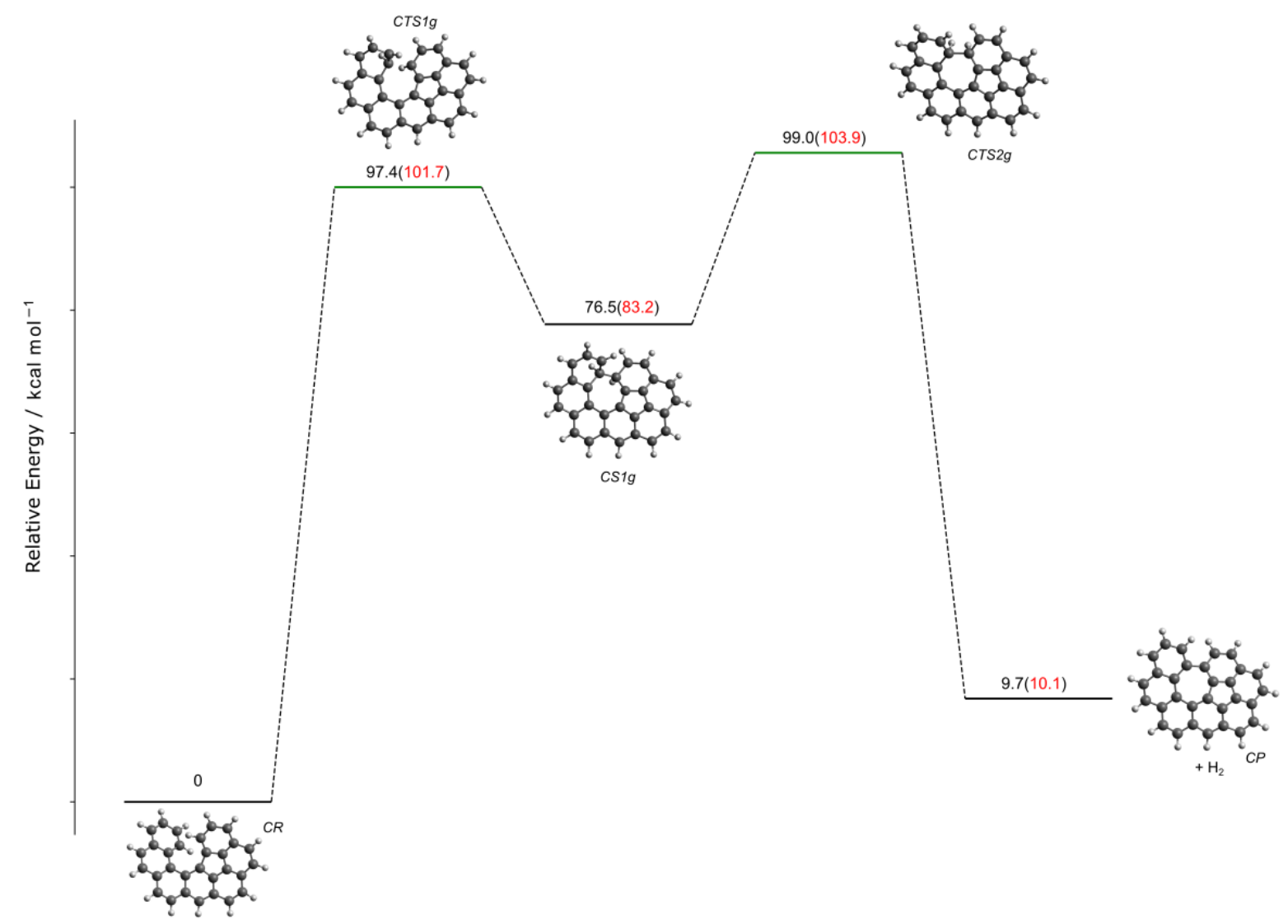

Figure 14: Potential Energy surface for the formation of a seven-member ring by direct cyclisation (pathway g) and bay closure in $\mathrm{PAH} \mathrm{C}$ at $0 \mathrm{~K}$. The relative energy of the different species are computed at both the M06-2X/cc-pVTZ and B3LYP/6-311+G(d,p) level of theory. 


\subsubsection{PAH D - H-abstraction facilitated bay closure pathways a and $b$}

Figure 15 presents the potential energy diagram for $\mathrm{H}$ abstraction facilitated seven-member ring bay closure in PAH D. The steps in this pathway are identical to those seen for PAH C. The barrier for the first abstraction step is very similar for both sites, at $18.1 \mathrm{kcal} / \mathrm{mol}$ and $17.7 \mathrm{kcal} / \mathrm{mol}$. These barriers are similar to abstractions from PAHs A,B, and C. The cyclisation steps in this PAH have similar barriers of 7.1 and $4.9 \mathrm{kcal} / \mathrm{mol}$, in contrast to $\mathrm{PAH} \mathrm{C}$ where the cyclisations had very different barriers depending on where the initial hydrogen abstraction occurred. The hydrogen loss steps again have the largest barriers in the process, and have close barriers of 32.6 and $32.0 \mathrm{kcal} / \mathrm{mol}$. This is very similar to what was observed for $\mathrm{PAH} \mathrm{C}$. The overall process is endothermic with $9.0 \mathrm{kcal} / \mathrm{mol}$ which is again very similar to $\mathrm{PAH}$ C. 


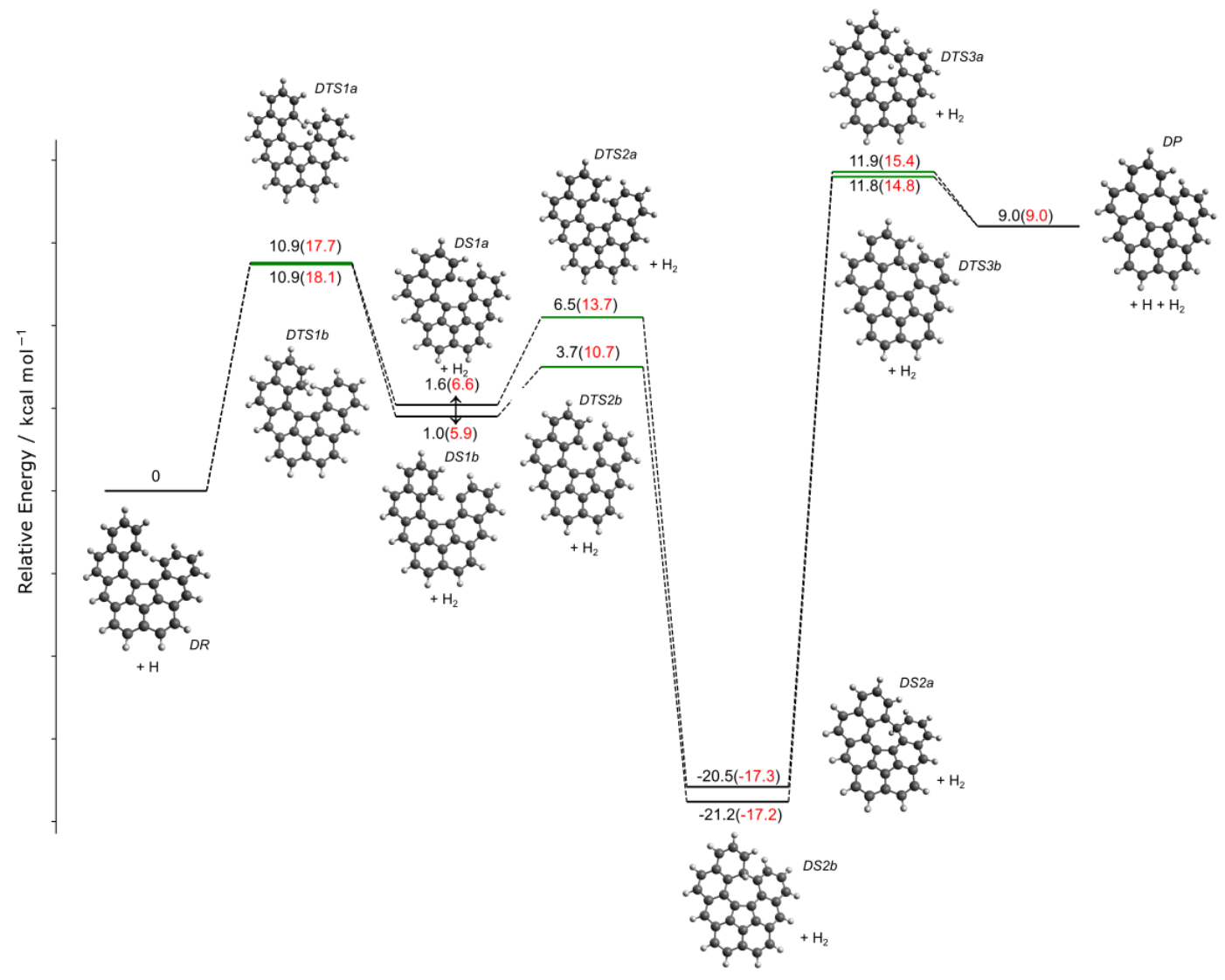

Figure 15: Potential Energy surface for the formation of a seven-member ring by hydrogen abstraction (pathways a and b) followed by cyclisation and bay closure in PAH D at $0 \mathrm{~K}$. The relative energy of the different species are computed at both the M06-2X/cc-pVTZ and B3LYP/6-311+G(d,p) level of theory.

\subsubsection{PAH D - H-addition facilitated bay closure pathways $c$ and $d$}

Figure 16 presents the potential energy diagram for $\mathrm{H}$ addition facilitated sevenmember ring bay closure in PAH D. The steps in this pathway are again identical to those seen for PAH C. The barriers also follow a similar trend to what was seen with PAH C. The initial hydrogen additions have very low barriers of 5.0 and $5.5 \mathrm{kcal} / \mathrm{mol}$ similar to what was observed with $\mathrm{PAH}$ C. The cyclisations have moderate barriers of 20.9 and $22.3 \mathrm{kcal} / \mathrm{mol}$. The hydrogen loss steps again have barriers similar for the other routes, at barriers of $35.7 \mathrm{kcal} / \mathrm{mol}$ and $34.4 \mathrm{kcal} / \mathrm{mol}$, whilst the $\mathrm{H}_{2}$ loss steps have extremely large barriers of 100 and $99.1 \mathrm{kcal} / \mathrm{mol}$ similar to other barriers for $\mathrm{H}_{2}$ loss at a free edge. Finally, the last hydrogen migrations have low barriers of 2.8 and $3.7 \mathrm{kcal} / \mathrm{mol}$ which is similar to what is seen for PAH C as well. The only 
significant difference between PAH C and D is that the cyclisation steps in pathways $\mathrm{c}$ and $\mathrm{d}$ have very similar barriers whereas the barriers were quite different between pathways $\mathrm{c}$ and $\mathrm{d}$ in $\mathrm{PAH} \mathrm{C}$.

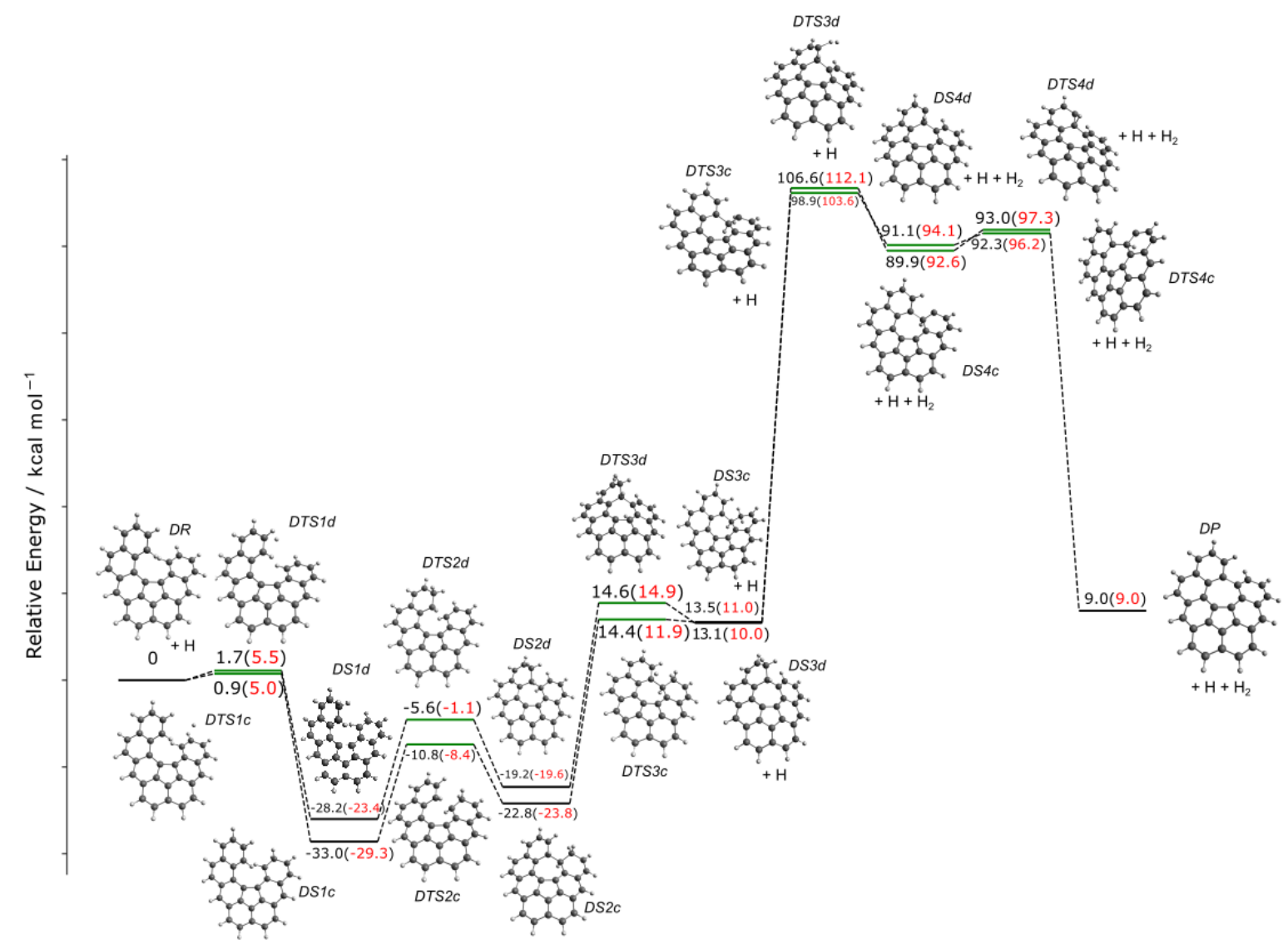

Figure 16: Potential Energy surface for the formation of a seven-member ring by hydrogen addition (pathways c and d) followed by cyclisation and bay closure in PAH D at $0 \mathrm{~K}$. The relative energy of the different species are computed at both the M06-2X/cc-pVTZ and B3LYP/6-311+G(d,p) level of theory.

\subsubsection{PAH D - Carbene facilitated bay closure pathways $e$ and $f$}

Figure 17 presents the potential energy diagram from carbene formation facilitated seven-member ring bay closure in PAH D. The steps in this pathway are essentially the same as for PAH C, as are the general trends and values for barriers. The initial hydrogen migration step to form the carbene site again has very high barriers for both potential carbenes, at 83.4 and $86.2 \mathrm{kcal} / \mathrm{mol}$. The subsequent cyclisations 
have much lower barriers of 11.9 and $8.9 \mathrm{kcal} / \mathrm{mol}$, although these are noticeably larger than those for PAH C. Additionally, in this case the resulting structures after the bay closures are very similar, but they do have quite different energies at 72.7 and $50.2 \mathrm{kcal} / \mathrm{mol}$ respectively. For the higher energy structure, the first migration has a very low barrier of $4.6 \mathrm{kcal} / \mathrm{mol}$. This is followed by a hydrogen migration with a much larger barrier of $40.0 \mathrm{kcal} / \mathrm{mol}$. The final $\mathrm{H}_{2}$ loss occurs across a free edge and has a characteristically high barrier of $88.5 \mathrm{kcal} / \mathrm{mol}$, similar to what was seen for PAH C. The lower energy pathway has an initial migration with a moderate barrier of $27.8 \mathrm{kcal} / \mathrm{mol}$, which is again followed by a much more difficult migration requiring $60.0 \mathrm{kcal} / \mathrm{mol}$. These barriers are higher than the high energy pathway, but as a consequence, the final $\mathrm{H}_{2}$ migration occurs across an armchair configuration, and has a much lower $29.9 \mathrm{kcal} / \mathrm{mol}$ barrier as a result.

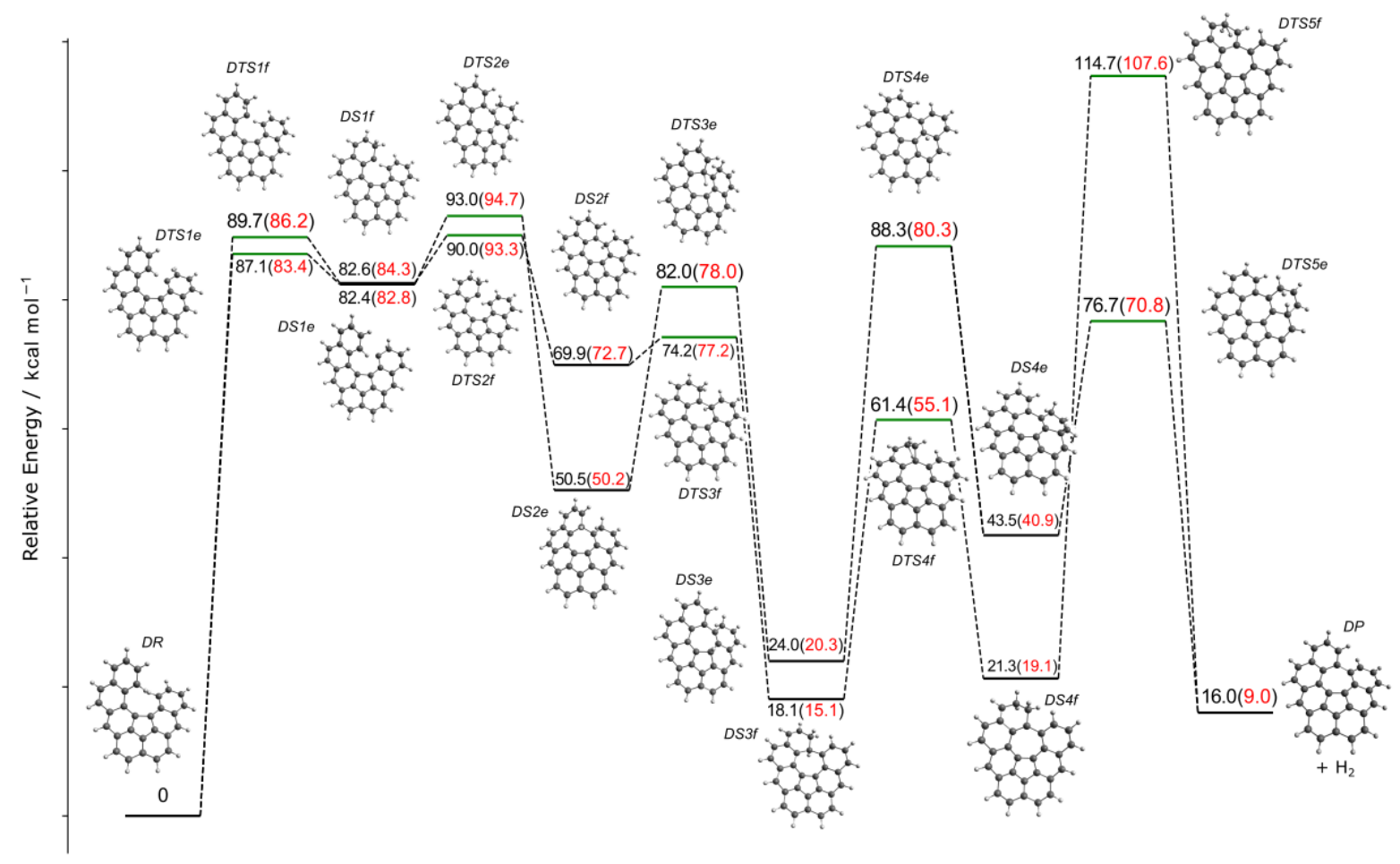

Figure 17: Potential Energy surface for the formation of a seven-member ring by carbene formation (pathways e and $\mathrm{f}$ ) followed by cyclisation and bay closure in PAH D at $0 \mathrm{~K}$. The relative energy of the different species are computed at both the M06-2X/cc-pVTZ and B3LYP/6-311+G(d,p) level of theory. 


\subsubsection{PAH D - Direct cyclisation bay closure pathways $g$ and $h$}

Figure 18 presents the potential energy diagram for direct cyclisation sevenmember ring bay closure in PAH D. This is the one pathway where PAH D is completely different to PAH C. The initial direct cyclisation has a very high barrier of $98.2 \mathrm{kcal} / \mathrm{mol}$, which is very similar to what was seen for PAH C. However, $\mathrm{H}_{2}$ loss immediately after cyclisation does not appear to occur in this case, and instead several hydrogen migrations are required until $\mathrm{H}_{2}$ loss can occur much like the carbene routes. In one case, only one hydrogen migration with a barrier of $43.5 \mathrm{kcal} / \mathrm{mol}$ is necessary before $\mathrm{H}_{2}$ loss can occur across an armchair configuration, requiring a lower barrier of $23.4 \mathrm{kcal} / \mathrm{mol}$. In the other case, a long series of increasingly difficult hydrogen migrations are required, with the first having a barrier of $14.5 \mathrm{kcal} / \mathrm{mol}$, the next two having moderate barriers of 25.8 and $29.1 \mathrm{kcal} / \mathrm{mol}$ and the last having a much higher barrier of $59.4 \mathrm{kcal} / \mathrm{mol}$. The final $\mathrm{H}_{2}$ loss is also across a free edge, meaning its barrier is much higher at $82.9 \mathrm{kcal} / \mathrm{mol}$, consistent with other losses seen across a free edge or on a singular carbon.

Across all pathways, general observations are that abstraction-based pathways are limited by the hydrogen atom loss step, hydrogen addition pathways are limited by $\mathrm{H}_{2}$ loss, and carbene and direct cyclisation pathways are limited by the initial

carbene formation or cyclisation steps, as well as $\mathrm{H}_{2}$ loss when it occurs across a free edge. 


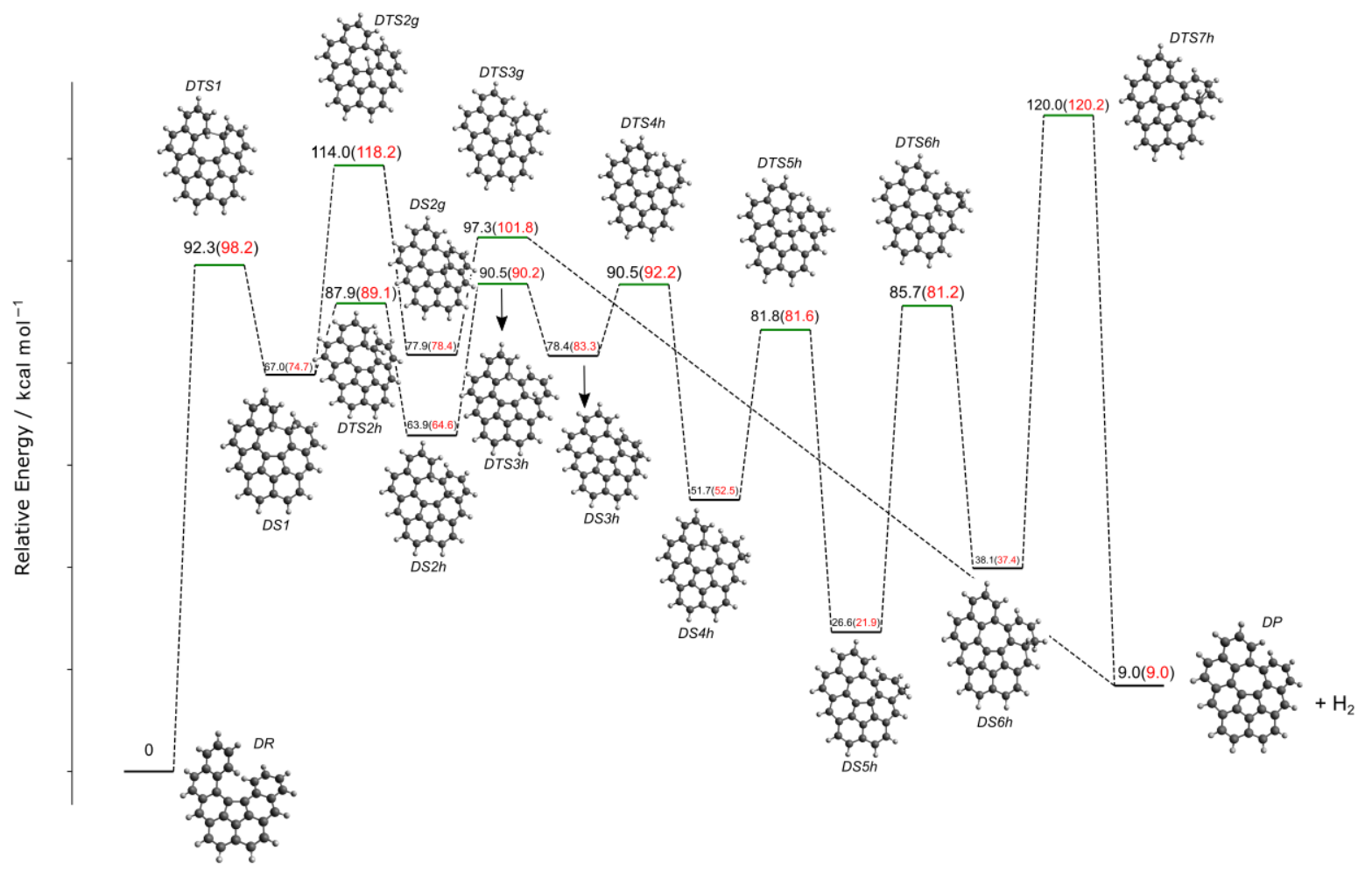

Figure 18: Potential Energy surface for the formation of a seven-member ring by direct cyclisation (pathways $\mathrm{g}$ and $\mathrm{h}$ ) and bay closure in PAH D at $0 \mathrm{~K}$. The relative energy of the different species are computed at both the M06-2X/cc-pVTZ and B3LYP/6-311+G(d,p) level of theory.

\subsubsection{All PAHs - conversion between hydrogen-abstracted radicals}

Figure 19 presents the hydrogen migration reactions that convert between the initial radicals formed by hydrogen migration, i.e. conversion between AS1a and AS1b. There is quite a spread of barriers, with the migration in PAH A having a very large barrier of $45.9 \mathrm{kcal} / \mathrm{mol}$ and thus unlikely. For PAHs B and C, the barriers $27.9 \mathrm{kcal} / \mathrm{mol}$ and $27.3 \mathrm{kcal} / \mathrm{mol}$ which is significantly easier than for PAH, but still substantial. For PAH D, the barrier is rather moderate at $13.2 \mathrm{kcal} / \mathrm{mol}$. However, in all cases, the barrier for acetylene addition or cyclisation after hydrogen abstraction is substantially lower than the intramolecular hydrogen migration, and so this path switching is not expected to impact the formation of the seven-member ring 


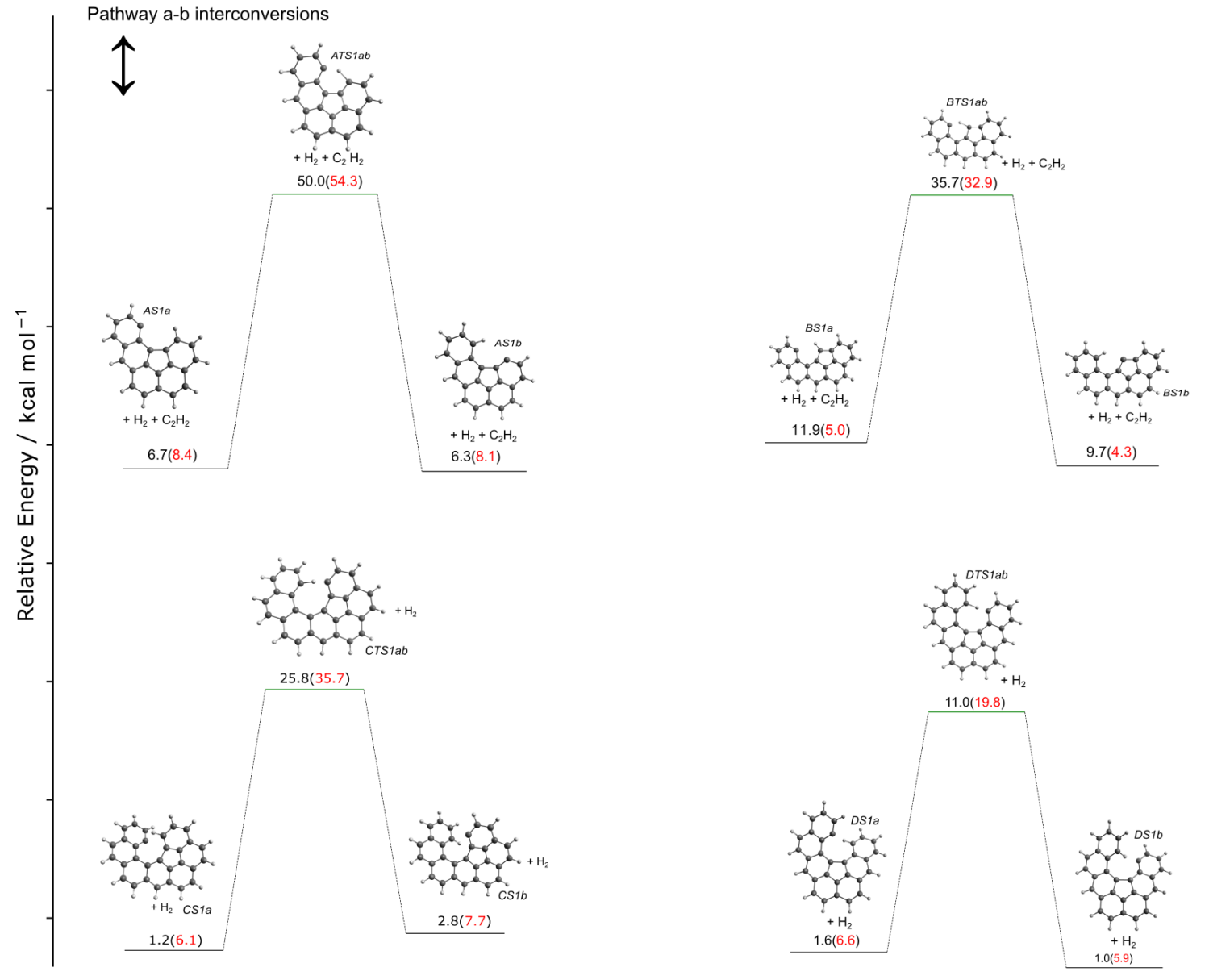

Figure 19: Potential Energy surface for the conversions of radicals between pathways a and b in HACA and hydrogen abstraction pathways. The relative energy of the different species are computed at both the M06-2X/cc-pVTZ and B3LYP/6-311+G(d,p) level of theory.

\subsection{Rate Constants}

The modified Arrhenius parameters, $A, n$, and $E_{A}$ are displayed in Table 1. These are fitted to the rate constants calculated at the M06-2X/cc-pVTZ//B3LYP/6$311 \mathrm{G}(\mathrm{d}, \mathrm{p})$ level of theory. The rates using only B3LYP have also been computed and can be found in the supplemental information. In general, the two functionals produce very similar rate constants, but the B3LYP functional tends to underestimate barriers and hence overestimate the rate constants at lower temperatures. The uncertainty in the rate constants is estimated as $\pm 2 \mathrm{kcal} / \mathrm{mol}$ in the activation energy, 
owing to the likely uncertainty in the barrier heights predicted by the M06-2X functional [56].

Table 1: Rate constants for all pathways at the M06-2X/cc-pVTZ//B3LYP/6-311G(d,p) level of theory. The units are $\mathrm{cm}$, kcal, mol, K, and s.

\begin{tabular}{|c|c|c|c|c|}
\hline Number & Reaction & $A$ & $n$ & $E_{A}$ \\
\hline $1 \mathrm{a}$ & $\mathrm{AR}+\mathrm{H} \rightarrow \mathrm{AS} 1 \mathrm{a}+\mathrm{H}_{2}$ & $5.90 \times 10^{7}$ & 1.85 & 17.12 \\
\hline$-1 \mathrm{a}$ & $\mathrm{AS} 1 \mathrm{a}+\mathrm{H}_{2} \rightarrow \mathrm{AR}+\mathrm{H}$ & $1.21 \times 10^{5}$ & 2.23 & 7.72 \\
\hline $1 b$ & $\mathrm{AR}+\mathrm{H} \rightarrow \mathrm{AS} 1 \mathrm{~b}+\mathrm{H}_{2}$ & $5.31 \times 10^{7}$ & 1.86 & 16.12 \\
\hline$-1 b$ & $\mathrm{AS} 1 \mathrm{~b}+\mathrm{H}_{2} \rightarrow \mathrm{AR}+\mathrm{H}$ & $9.16 \times 10^{4}$ & 2.28 & 7.01 \\
\hline $1 \mathrm{ab}$ & $\mathrm{AS} 1 \mathrm{a} \rightarrow \mathrm{AS} 1 \mathrm{~b}$ & $7.81 \times 10^{10}$ & 0.44 & 41.76 \\
\hline$-1 a b$ & $\mathrm{AS} 1 \mathrm{~b} \rightarrow \mathrm{AS} 1 \mathrm{a}$ & $6.23 \times 10^{10}$ & 0.48 & 42.04 \\
\hline $2 \mathrm{a}$ & $\mathrm{AS} 1 \mathrm{a}+\mathrm{C}_{2} \mathrm{H}_{2} \rightarrow \mathrm{AS} 2 \mathrm{a}$ & $1.345 \times 10^{3}$ & 2.57 & 4.94 \\
\hline$-2 a$ & $\mathrm{AS} 2 \mathrm{a} \rightarrow \mathrm{AS} 1 \mathrm{a}+\mathrm{C}_{2} \mathrm{H}_{2}$ & $2.37 \times 10^{12}$ & 0.71 & 39.67 \\
\hline $2 \mathrm{~b}$ & $\mathrm{AS} 1 \mathrm{~b}+\mathrm{C}_{2} \mathrm{H}_{2} \rightarrow \mathrm{AS} 2 \mathrm{~b}$ & $3.52 \times 10^{3}$ & 2.60 & 4.00 \\
\hline$-2 b$ & $\mathrm{AS} 2 \mathrm{~b} \rightarrow \mathrm{AS} 1 \mathrm{~b}+\mathrm{C}_{2} \mathrm{H}_{2}$ & $4.74 \times 10^{12}$ & 0.70 & 40.80 \\
\hline $3 a$ & $\mathrm{AS} 2 \mathrm{a} \rightarrow \mathrm{AS} 3 \mathrm{a}$ & $1.96 \times 10^{11}$ & 0.11 & 25.33 \\
\hline$-3 a$ & $\mathrm{AS} 3 \mathrm{a} \rightarrow \mathrm{AS} 2 \mathrm{a}$ & $3.41 \times 10^{11}$ & 0.63 & 53.37 \\
\hline $3 b$ & $\mathrm{AS} 2 \mathrm{~b} \rightarrow \mathrm{AS} 3 \mathrm{~b}$ & $1.13 \times 10^{11}$ & 0.13 & 30.51 \\
\hline$-3 b$ & $\mathrm{AS} 3 \mathrm{~b} \rightarrow \mathrm{AS} 2 \mathrm{~b}$ & $2.38 \times 10^{11}$ & 0.60 & 57.90 \\
\hline $4 a$ & $\mathrm{AS} 3 \mathrm{a} \rightarrow \mathrm{AP}+\mathrm{H}$ & $1.77 \times 10^{10}$ & 1.09 & 27.15 \\
\hline$-4 a$ & $\mathrm{AP}+\mathrm{H} \rightarrow \mathrm{AS} 3 \mathrm{a}$ & $5.32 \times 10^{7}$ & 1.51 & 7.10 \\
\hline $4 b$ & $\mathrm{AS} 3 \mathrm{~b} \rightarrow \mathrm{AP}+\mathrm{H}$ & $1.51 \times 10^{10}$ & 1.08 & 28.84 \\
\hline$-4 b$ & $\mathrm{AP}+\mathrm{H} \rightarrow \mathrm{AS} 3 \mathrm{~b}$ & $5.84 \times 10^{7}$ & 1.53 & 7.08 \\
\hline $2 \mathrm{am}$ & $\mathrm{AS} 2 \mathrm{a} \rightarrow \mathrm{AS} 2 \mathrm{am}$ & $1.83 \times 10^{11}$ & 0.37 & 25.83 \\
\hline$-2 \mathrm{am}$ & $\mathrm{AS} 2 \mathrm{am} \rightarrow \mathrm{AS} 2 \mathrm{a}$ & $3.59 \times 10^{10}$ & 0.53 & 29.67 \\
\hline $2 \mathrm{bm}$ & $\mathrm{AS} 2 \mathrm{~b} \rightarrow \mathrm{AS} 2 \mathrm{bm}$ & $8.16 \times 10^{10}$ & 0.37 & 32.09 \\
\hline$-2 b m$ & $\mathrm{AS} 2 \mathrm{bm} \rightarrow \mathrm{AS} 2 \mathrm{~b}$ & $4.64 \times 10^{9}$ & 0.48 & 35.31 \\
\hline $3 a m$ & AS2am $\rightarrow$ AS3am & $8.54 \times 10^{11}$ & 0.05 & 4.25 \\
\hline$-3 a m$ & AS3am $\rightarrow$ AS2am & $1.57 \times 10^{11}$ & 0.48 & 45.50 \\
\hline $3 \mathrm{bm}$ & $\mathrm{AS} 2 \mathrm{bm} \rightarrow \mathrm{AS} 3 \mathrm{bm}$ & $1.03 \times 10^{11}$ & 0.04 & 2.30 \\
\hline$-3 \mathrm{bm}$ & $\mathrm{AS} 3 \mathrm{bm} \rightarrow \mathrm{AS} 2 \mathrm{bm}$ & $1.56 \times 10^{12}$ & 0.60 & 43.35 \\
\hline $4 \mathrm{am}$ & $\mathrm{AS} 3 \mathrm{am} \rightarrow \mathrm{AP}+\mathrm{H}$ & $1.02 \times 10^{9}$ & 1.22 & 40.86 \\
\hline
\end{tabular}


Table 1: Continued from previous page.

\begin{tabular}{|c|c|c|c|c|}
\hline Number & Reaction & $A$ & $n$ & $E_{A}$ \\
\hline$-4 a m$ & $\mathrm{AP}+\mathrm{H} \rightarrow \mathrm{AS} 3 \mathrm{am}$ & $3.91 \times 10^{8}$ & 1.53 & 3.62 \\
\hline $4 \mathrm{bm}$ & $\mathrm{AS} 3 \mathrm{bm} \rightarrow \mathrm{AP}+\mathrm{H}$ & $1.21 \times 10^{10}$ & 1.30 & 42.21 \\
\hline$-4 \mathrm{bm}$ & $\mathrm{AP}+\mathrm{H} \rightarrow \mathrm{AS} 3 \mathrm{bm}$ & $3.02 \times 10^{8}$ & 1.53 & 3.43 \\
\hline $2 \mathrm{al}$ & $\mathrm{AS} 2 \mathrm{a} \rightarrow \mathrm{ASPa}+\mathrm{H}$ & $8.36 \times 10^{09}$ & 1.41 & 35.85 \\
\hline$-2 a l$ & $\mathrm{ASPa}+\mathrm{H} \rightarrow \mathrm{AS} 2 \mathrm{a}$ & $5.30 \times 10^{08}$ & 1.53 & 5.50 \\
\hline $2 \mathrm{bl}$ & $\mathrm{AS} 2 \mathrm{~b} \rightarrow \mathrm{ASPb}+\mathrm{H}$ & $4.30 \times 10^{09}$ & 1.44 & 36.12 \\
\hline$-2 b l$ & $\mathrm{ASPb}+\mathrm{H} \rightarrow \mathrm{AS} 2 \mathrm{~b}$ & $3.41 \times 10^{8}$ & 1.56 & 6.50 \\
\hline $1 \mathrm{a}$ & $\mathrm{BR}+\mathrm{H} \rightarrow \mathrm{BS} 1 \mathrm{a}+\mathrm{H}_{2}$ & $6.59 \times 10^{7}$ & 1.77 & 14.77 \\
\hline$-1 \mathrm{a}$ & $\mathrm{BS} 1 \mathrm{a}+\mathrm{H}_{2} \rightarrow \mathrm{BR}+\mathrm{H}$ & $1.15 \times 10^{5}$ & 2.31 & 8.82 \\
\hline $1 b$ & $\mathrm{BR}+\mathrm{H} \rightarrow \mathrm{BS} 1 \mathrm{~b}+\mathrm{H}_{2}$ & $1.48 \times 10^{7}$ & 1.86 & 17.07 \\
\hline$-1 b$ & $\mathrm{BS} 1 \mathrm{~b}+\mathrm{H}_{2} \rightarrow \mathrm{BR}+\mathrm{H}$ & $5.91 \times 10^{4}$ & 2.23 & 11.87 \\
\hline $1 a b$ & $\mathrm{BS} 1 \mathrm{a} \rightarrow \mathrm{BS} 1 \mathrm{~b}$ & $3.86 \times 10^{11}$ & 0.35 & 24.41 \\
\hline$-1 a b$ & $\mathrm{BS} 1 \mathrm{~b} \rightarrow \mathrm{BS} 1 \mathrm{a}$ & $1.39 \times 10^{11}$ & 0.54 & 23.66 \\
\hline $2 \mathrm{a}$ & $\mathrm{BS} 1 \mathrm{a}+\mathrm{C}_{2} \mathrm{H}_{2} \rightarrow \mathrm{BS} 2 \mathrm{a}$ & $3.89 \times 10^{3}$ & 2.59 & 4.01 \\
\hline$-2 \mathrm{a}$ & $\mathrm{BS} 2 \mathrm{a} \rightarrow \mathrm{BS} 1 \mathrm{a}+\mathrm{C}_{2} \mathrm{H}_{2}$ & $6.51 \times 10^{12}$ & 0.71 & 45.04 \\
\hline $2 b$ & $\mathrm{BS} 1 \mathrm{~b}+\mathrm{C}_{2} \mathrm{H}_{2} \rightarrow \mathrm{BS} 2 \mathrm{~b}$ & $1.10 \times 10^{3}$ & 2.58 & 7.65 \\
\hline$-2 b$ & $\mathrm{BS} 2 \mathrm{~b} \rightarrow \mathrm{BS} 1 \mathrm{~b}+\mathrm{C}_{2} \mathrm{H}_{2}$ & $2.89 \times 10^{12}$ & 0.71 & 38.30 \\
\hline $3 a$ & $\mathrm{BS} 2 \mathrm{a} \rightarrow \mathrm{BS} 3 \mathrm{a}$ & $5.75 \times 10^{11}$ & 0.07 & 2.98 \\
\hline$-3 a$ & $\mathrm{BS} 3 \mathrm{a} \rightarrow \mathrm{BS} 2 \mathrm{a}$ & $1.74 \times 10^{12}$ & 0.42 & 29.04 \\
\hline $3 b$ & $\mathrm{BS} 2 \mathrm{~b} \rightarrow \mathrm{BS} 3 \mathrm{~b}$ & $5.10 \times 10^{11}$ & 0.14 & 19.74 \\
\hline$-3 b$ & $\mathrm{BS} 3 \mathrm{~b} \rightarrow \mathrm{BS} 2 \mathrm{~b}$ & $9.94 \times 10^{11}$ & 0.41 & 45.26 \\
\hline $4 a$ & $\mathrm{BS} 3 \mathrm{a} \rightarrow \mathrm{BP}+\mathrm{H}$ & $3.21 \times 10^{10}$ & 0.96 & 23.13 \\
\hline$-4 a$ & $\mathrm{BP}+\mathrm{H} \rightarrow \mathrm{BS} 3 \mathrm{a}$ & $1.29 \times 10^{8}$ & 1.51 & 7.42 \\
\hline $4 \mathrm{~b}$ & $\mathrm{BS} 3 \mathrm{~b} \rightarrow \mathrm{BP}+\mathrm{H}$ & $3.59 \times 10^{11}$ & 0.60 & 30.05 \\
\hline$-4 b$ & $\mathrm{BP}+\mathrm{H} \rightarrow \mathrm{BS} 3 \mathrm{~b}$ & $6.26 \times 10^{8}$ & 1.38 & 24.51 \\
\hline 2am & $\mathrm{BS} 2 \mathrm{a} \rightarrow \mathrm{BS} 2 \mathrm{am}$ & $1.67 \times 10^{11}$ & 0.48 & 20.79 \\
\hline$-2 \mathrm{am}$ & $\mathrm{BS} 2 \mathrm{am} \rightarrow \mathrm{BS} 2 \mathrm{a}$ & $1.73 \times 10^{10}$ & 0.80 & 22.17 \\
\hline $2 \mathrm{bm}$ & $\mathrm{BS} 2 \mathrm{~b} \rightarrow \mathrm{BS} 2 \mathrm{bm}$ & $7.02 \times 10^{10}$ & 0.71 & 12.92 \\
\hline$-2 \mathrm{bm}$ & $\mathrm{BS} 2 \mathrm{bm} \rightarrow \mathrm{BS} 2 \mathrm{~b}$ & $4.80 \times 10^{10}$ & 0.75 & 11.61 \\
\hline $3 a m$ & $\mathrm{BS} 2 \mathrm{am} \rightarrow \mathrm{BS} 3 \mathrm{am}$ & $1.51 \times 10^{12}$ & 0.07 & 5.00 \\
\hline
\end{tabular}

Continued on next page. 
Table 1: Continued from previous page.

\begin{tabular}{|c|c|c|c|c|}
\hline Number & Reaction & $A$ & $n$ & $E_{A}$ \\
\hline$-3 a m$ & BS3am $\rightarrow$ BS2am & $4.00 \times 10^{11}$ & 0.48 & 50.81 \\
\hline $3 \mathrm{bm}$ & $\mathrm{BS} 2 \mathrm{bm} \rightarrow \mathrm{BS} 3 \mathrm{bm}$ & $1.00 \times 10^{12}$ & 0.10 & 6.42 \\
\hline$-3 b m$ & $\mathrm{BS} 3 \mathrm{bm} \rightarrow \mathrm{BS} 2 \mathrm{bm}$ & $2.13 \times 10^{12}$ & 0.37 & 33.75 \\
\hline $4 \mathrm{am}$ & $\mathrm{BS} 3 \mathrm{am} \rightarrow \mathrm{BP}+\mathrm{H}$ & $2.37 \times 10^{9}$ & 1.18 & 30.77 \\
\hline$-4 a m$ & $\mathrm{BP}+\mathrm{H} \rightarrow \mathrm{BS} 3 \mathrm{am}$ & $3.53 \times 10^{8}$ & 1.49 & 3.44 \\
\hline $4 \mathrm{bm}$ & $\mathrm{BS} 3 \mathrm{bm} \rightarrow \mathrm{BP}+\mathrm{H}$ & $1.74 \times 10^{10}$ & 0.96 & 28.25 \\
\hline$-4 \mathrm{bm}$ & $\mathrm{BP}+\mathrm{H} \rightarrow \mathrm{BS} 3 \mathrm{bm}$ & $2.06 \times 10^{8}$ & 1.51 & 12.44 \\
\hline 2al & $\mathrm{BS} 2 \mathrm{a} \rightarrow \mathrm{BSPa}+\mathrm{H}$ & $4.30 \times 10^{09}$ & 1.40 & 39.04 \\
\hline$-2 \mathrm{al}$ & $\mathrm{BSPa}+\mathrm{H} \rightarrow \mathrm{BS} 2 \mathrm{a}$ & $2.44 \times 10^{08}$ & 1.52 & 6.04 \\
\hline $2 \mathrm{bl}$ & $\mathrm{BS} 2 \mathrm{~b} \rightarrow \mathrm{BSPb}+\mathrm{H}$ & $3.20 \times 10^{09}$ & 1.48 & 39.19 \\
\hline$-2 b l$ & $\mathrm{BSPb}+\mathrm{H} \rightarrow \mathrm{BS} 2 \mathrm{~b}$ & $2.77 \times 10^{8}$ & 1.52 & 5.30 \\
\hline $2 \mathrm{bsv}$ & $\mathrm{BS} 2 \mathrm{~b} \rightarrow \mathrm{BS} 2 \mathrm{sv}$ & $3.02 \times 10^{11}$ & 0.30 & 35.35 \\
\hline$-2 \mathrm{bsv}$ & $\mathrm{BS} 2 \mathrm{~b} \rightarrow \mathrm{BS} 2 \mathrm{sv}$ & $1.32 \times 10^{12}$ & 0.34 & 10.10 \\
\hline $3 \mathrm{bsv}$ & $\mathrm{BS} 2 \mathrm{sv} \rightarrow \mathrm{BS} 3 \mathrm{sv}$ & $2.28 \times 10^{12}$ & 0.27 & 13.29 \\
\hline$-3 \mathrm{bsv}$ & $\mathrm{BS} 2 \mathrm{sv} \rightarrow \mathrm{BS} 3 \mathrm{sv}$ & $8.85 \times 10^{10}$ & 0.47 & 46.88 \\
\hline $1 \mathrm{p}$ & $\mathrm{BP}+\mathrm{H} \rightarrow \mathrm{BP} 1$ & $3.48 \times 10^{8}$ & 1.49 & 3.44 \\
\hline$-1 p$ & $\mathrm{BP} 1 \rightarrow \mathrm{BP}+\mathrm{H}$ & $2.34 \times 10^{9}$ & 1.18 & 30.77 \\
\hline $2 \mathrm{p}$ & $\mathrm{BP} 1 \rightarrow \mathrm{BP} 2$ & $2.12 \times 10^{10}$ & 0.67 & 40.32 \\
\hline$-2 \mathrm{p}$ & $\mathrm{BP} 2 \rightarrow \mathrm{BP} 1$ & $8.39 \times 10^{11}$ & 0.29 & 18.61 \\
\hline $3 \mathrm{p}$ & $\mathrm{BP} 2 \rightarrow \mathrm{BP} 3$ & $1.03 \times 10^{12}$ & 0.15 & 9.25 \\
\hline$-3 p$ & $\mathrm{BP} 3 \rightarrow \mathrm{BP} 2$ & $1.87 \times 10^{12}$ & 0.32 & 15.04 \\
\hline $4 \mathrm{p}$ & $\mathrm{BP} 3 \rightarrow \mathrm{BP} 4$ & $6.65 \times 10^{12}$ & -0.13 & 4.09 \\
\hline$-4 p$ & $\mathrm{BP} 4 \rightarrow \mathrm{BP} 3$ & $1.52 \times 10^{12}$ & 0.00 & 34.08 \\
\hline $5 \mathrm{p}$ & $\mathrm{BP} 4 \rightarrow \mathrm{BF}+\mathrm{H}$ & $1.13 \times 10^{10}$ & 1.00 & 15.65 \\
\hline$-5 p$ & $\mathrm{BF}+\mathrm{H} \rightarrow \mathrm{BP} 4$ & $2.82 \times 10^{8}$ & 1.36 & 35.44 \\
\hline $1 \mathrm{a}$ & $\mathrm{CR}+\mathrm{H} \rightarrow \mathrm{CS} 1 \mathrm{a}+\mathrm{H}_{2}$ & $4.20 \times 10^{7}$ & 1.87 & 16.00 \\
\hline$-1 \mathrm{a}$ & $\mathrm{CS} 1 \mathrm{a}+\mathrm{H}_{2} \rightarrow \mathrm{CR}+\mathrm{H}$ & $2.79 \times 10^{5}$ & 2.06 & 7.54 \\
\hline $1 b$ & $\mathrm{CR}+\mathrm{H} \rightarrow \mathrm{CS} 1 \mathrm{~b}+\mathrm{H}_{2}$ & $3.59 \times 10^{7}$ & 1.87 & 16.21 \\
\hline$-1 b$ & $\mathrm{CS} 1 \mathrm{~b}+\mathrm{H}_{2} \rightarrow \mathrm{CR}+\mathrm{H}$ & $2.93 \times 10^{5}$ & 2.04 & 9.32 \\
\hline $1 \mathrm{ab}$ & $\mathrm{CS} 1 \mathrm{a} \rightarrow \mathrm{CS} 1 \mathrm{~b}$ & $7.83 \times 10^{10}$ & 0.83 & 22.80 \\
\hline
\end{tabular}

Continued on next page. 
Table 1: Continued from previous page.

\begin{tabular}{|c|c|c|c|c|}
\hline Number & Reaction & $A$ & $n$ & $E_{A}$ \\
\hline$-1 a b$ & $\mathrm{CS} 1 \mathrm{~b} \rightarrow \mathrm{CS} 1 \mathrm{a}$ & $9.61 \times 10^{10}$ & 0.81 & 24.36 \\
\hline $2 \mathrm{a}$ & $\mathrm{CS} 1 \mathrm{a} \rightarrow \mathrm{CS} 2 \mathrm{a}$ & $6.74 \times 10^{11}$ & 0.17 & 6.94 \\
\hline$-2 \mathrm{a}$ & $\mathrm{CS} 2 \mathrm{a} \rightarrow \mathrm{CS} 1 \mathrm{a}$ & $1.65 \times 10^{12}$ & 0.39 & 28.64 \\
\hline $2 \mathrm{~b}$ & $\mathrm{CS} 1 \mathrm{~b} \rightarrow \mathrm{CS} 2 \mathrm{~b}$ & $5.12 \times 10^{11}$ & 0.26 & 12.94 \\
\hline$-2 b$ & $\mathrm{CS} 2 \mathrm{~b} \rightarrow \mathrm{CS} 1 \mathrm{~b}$ & $1.08 \times 10^{12}$ & 0.54 & 31.94 \\
\hline $3 \mathrm{a}$ & $\mathrm{CS} 2 \mathrm{a} \rightarrow \mathrm{CP}+\mathrm{H}$ & $6.05 \times 10^{9}$ & 1.22 & 31.47 \\
\hline$-3 a$ & $\mathrm{CP}+\mathrm{H} \rightarrow \mathrm{CS} 2 \mathrm{a}$ & $1.37 \times 10^{8}$ & 1.46 & 6.78 \\
\hline $3 \mathrm{~b}$ & $\mathrm{CS} 2 \mathrm{~b} \rightarrow \mathrm{CP}+\mathrm{H}$ & $4.39 \times 10^{9}$ & 1.32 & 29.31 \\
\hline$-3 b$ & $\mathrm{CP}+\mathrm{H} \rightarrow \mathrm{CS} 2 \mathrm{~b}$ & $9.41 \times 10^{7}$ & 1.49 & 24.14 \\
\hline 1c & $\mathrm{CR}+\mathrm{H} \rightarrow \mathrm{CS} 1 \mathrm{c}$ & $2.48 \times 10^{8}$ & 1.54 & 5.53 \\
\hline$-1 c$ & $\mathrm{CS} 1 \mathrm{c} \rightarrow \mathrm{CR}+\mathrm{H}$ & $2.29 \times 10^{10}$ & 1.00 & 30.41 \\
\hline $1 d$ & $\mathrm{CR}+\mathrm{H} \rightarrow \mathrm{CS} 1 \mathrm{~d}$ & $2.28 \times 10^{8}$ & 1.52 & 4.57 \\
\hline$-1 d$ & $\mathrm{CS} 1 \mathrm{~d} \rightarrow \mathrm{CR}+\mathrm{H}$ & $1.71 \times 10^{10}$ & 1.01 & 29.00 \\
\hline $2 \mathrm{c}$ & $\mathrm{CS} 1 \mathrm{c} \rightarrow \mathrm{CS} 2 \mathrm{c}$ & $2.26 \times 10^{11}$ & 0.19 & 33.08 \\
\hline$-2 c$ & $\mathrm{CS} 2 \mathrm{c} \rightarrow \mathrm{CS} 1 \mathrm{c}$ & $2.25 \times 10^{11}$ & 0.43 & 9.69 \\
\hline $2 \mathrm{~d}$ & $\mathrm{CS} 1 \mathrm{~d} \rightarrow \mathrm{CS} 2 \mathrm{~d}$ & $5.54 \times 10^{11}$ & 0.02 & 17.98 \\
\hline$-2 \mathrm{~d}$ & $\mathrm{CS} 2 \mathrm{~d} \rightarrow \mathrm{CS} 1 \mathrm{~d}$ & $1.49 \times 10^{12}$ & 0.40 & 16.05 \\
\hline $3 \mathrm{c}$ & $\mathrm{CS} 2 \mathrm{c} \rightarrow \mathrm{CS} 3 \mathrm{c}+\mathrm{H}$ & $8.55 \times 10^{9}$ & 1.08 & 35.25 \\
\hline$-3 c$ & $\mathrm{CS} 3 \mathrm{c}+\mathrm{H} \rightarrow \mathrm{CS} 2 \mathrm{c}$ & $2.21 \times 10^{8}$ & 1.56 & 3.28 \\
\hline $3 \mathrm{~d}$ & $\mathrm{CS} 2 \mathrm{~d} \rightarrow \mathrm{CS} 3 \mathrm{~d}+\mathrm{H}$ & $3.21 \times 10^{10}$ & 1.14 & 36.00 \\
\hline$-3 d$ & $\mathrm{CS} 3 \mathrm{~d}+\mathrm{H} \rightarrow \mathrm{CS} 2 \mathrm{~d}$ & $2.26 \times 10^{8}$ & 1.55 & 3.11 \\
\hline $4 \mathrm{c}$ & $\mathrm{CS} 3 \mathrm{c} \rightarrow \mathrm{CS} 4 \mathrm{c}+\mathrm{H}_{2}$ & $1.18 \times 10^{9}$ & 1.65 & 86.44 \\
\hline$-4 c$ & $\mathrm{CS} 4 \mathrm{c}+\mathrm{H}_{2} \rightarrow \mathrm{CS} 3 \mathrm{c}$ & $2.35 \times 10^{5}$ & 1.97 & 17.19 \\
\hline $4 d$ & $\mathrm{CS} 3 \mathrm{~d} \rightarrow \mathrm{CS} 4 \mathrm{~d}+\mathrm{H}_{2}$ & $1.47 \times 10^{9}$ & 1.59 & 102.07 \\
\hline$-4 d$ & $\mathrm{CS} 4 \mathrm{~d}+\mathrm{H}_{2} \rightarrow \mathrm{CS} 3 \mathrm{~d}$ & $2.63 \times 10^{5}$ & 1.87 & 20.77 \\
\hline $5 c$ & $\mathrm{CS} 4 \mathrm{c} \rightarrow \mathrm{CP}$ & $7.55 \times 10^{11}$ & 0.39 & 4.13 \\
\hline$-5 c$ & $\mathrm{CP} \rightarrow \mathrm{CS} 4 \mathrm{c}$ & $4.66 \times 10^{10}$ & 0.88 & 94.28 \\
\hline $5 \mathrm{~d}$ & $\mathrm{CS} 4 \mathrm{~d} \rightarrow \mathrm{CP}$ & $1.49 \times 10^{12}$ & 0.39 & 4.82 \\
\hline$-5 d$ & $\mathrm{CP} \rightarrow \mathrm{CS} 4 \mathrm{~d}$ & $1.70 \times 10^{11}$ & 0.82 & 84.72 \\
\hline $1 \mathrm{e}$ & $\mathrm{CR} \rightarrow \mathrm{CS} 1 \mathrm{e}$ & $8.03 \times 10^{10}$ & 0.90 & 95.83 \\
\hline
\end{tabular}


Table 1: Continued from previous page.

\begin{tabular}{|c|c|c|c|c|}
\hline Number & Reaction & $A$ & $n$ & $E_{A}$ \\
\hline$-1 e$ & $\mathrm{CS} 1 \mathrm{e} \rightarrow \mathrm{CR}$ & $4.40 \times 10^{11}$ & 0.36 & 3.38 \\
\hline $1 f$ & $\mathrm{CR} \rightarrow \mathrm{CS} 1 \mathrm{f}$ & $1.06 \times 10^{11}$ & 0.80 & 84.26 \\
\hline$-1 f$ & $\mathrm{CS} 1 \mathrm{f} \rightarrow \mathrm{CR}$ & $5.49 \times 10^{11}$ & 0.34 & 2.01 \\
\hline $2 \mathrm{e}$ & $\mathrm{CS} 1 \mathrm{e} \rightarrow \mathrm{CS} 2 \mathrm{e}$ & $8.03 \times 10^{11}$ & 0.01 & 8.46 \\
\hline$-2 \mathrm{e}$ & $\mathrm{CS} 2 \mathrm{e} \rightarrow \mathrm{CS} 1 \mathrm{e}$ & $1.90 \times 10^{12}$ & 0.22 & 17.91 \\
\hline $2 f$ & $\mathrm{CS} 1 \mathrm{f} \rightarrow \mathrm{CS} 2 \mathrm{f}$ & $1.00 \times 10^{12}$ & -0.01 & 3.47 \\
\hline$-2 f$ & $\mathrm{CS} 2 \mathrm{f} \rightarrow \mathrm{CS} 1 \mathrm{f}$ & $2.17 \times 10^{12}$ & 0.56 & 59.28 \\
\hline $3 e$ & $\mathrm{CS} 2 \mathrm{e} \rightarrow \mathrm{CS} 3 \mathrm{e}$ & $5.76 \times 10^{11}$ & 0.39 & 0.87 \\
\hline$-3 e$ & $\mathrm{CS} 3 \mathrm{e} \rightarrow \mathrm{CS} 2 \mathrm{e}$ & $1.05 \times 10^{11}$ & 0.90 & 53.50 \\
\hline $3 f$ & $\mathrm{CS} 2 \mathrm{f} \rightarrow \mathrm{CS} 3 \mathrm{f}$ & $3.06 \times 10^{11}$ & 0.82 & 63.56 \\
\hline$-3 f$ & $\mathrm{CS} 3 \mathrm{f} \rightarrow \mathrm{CS} 2 \mathrm{f}$ & $1.51 \times 10^{10}$ & 0.67 & 50.31 \\
\hline $4 \mathrm{e}$ & $\mathrm{CS} 3 \mathrm{e} \rightarrow \mathrm{CS} 4 \mathrm{e}$ & $8.87 \times 10^{10}$ & 0.64 & 31.31 \\
\hline$-4 \mathrm{e}$ & $\mathrm{CS} 4 \mathrm{e} \rightarrow \mathrm{CS} 3 \mathrm{e}$ & $1.73 \times 10^{10}$ & 0.71 & 60.65 \\
\hline $4 \mathrm{f}$ & $\mathrm{CS} 3 \mathrm{f} \rightarrow \mathrm{CP}+\mathrm{H}_{2}$ & $4.48 \times 10^{9}$ & 0.71 & 27.10 \\
\hline$-4 f$ & $\mathrm{CP}+\mathrm{H}_{2} \rightarrow \mathrm{CS} 3 \mathrm{f}$ & $2.33 \times 10^{5}$ & 1.74 & 55.10 \\
\hline $5 e$ & $\mathrm{CS} 4 \mathrm{e} \rightarrow \mathrm{CP}+\mathrm{H}_{2}$ & $3.91 \times 10^{09}$ & 1.27 & 97.14 \\
\hline$-5 \mathrm{e}$ & $\mathrm{CP}+\mathrm{H}_{2} \rightarrow \mathrm{CS} 4 \mathrm{e}$ & $2.45 \times 10^{5}$ & 2.00 & 86.40 \\
\hline $1 g$ & $\mathrm{CR} \rightarrow \mathrm{CS} 1 \mathrm{~g}$ & $1.53 \times 10^{11}$ & 0.52 & 101.74 \\
\hline$-1 g$ & $\mathrm{CS} 1 \mathrm{~g} \rightarrow \mathrm{CR}$ & $2.86 \times 10^{12}$ & 0.37 & 18.93 \\
\hline $2 \mathrm{~g}$ & $\mathrm{CS} 1 \mathrm{~g} \rightarrow \mathrm{CP}+\mathrm{H}_{2}$ & $2.83 \times 10^{10}$ & 1.02 & 19.73 \\
\hline$-2 g$ & $\mathrm{CP}+\mathrm{H}_{2} \rightarrow \mathrm{CS} 1 \mathrm{~g}$ & $4.37 \times 10^{4}$ & 2.16 & 90.76 \\
\hline $1 \mathrm{a}$ & $\mathrm{DR}+\mathrm{H} \rightarrow \mathrm{DS} 1 \mathrm{a}+\mathrm{H}_{2}$ & $2.77 \times 10^{7}$ & 1.91 & 16.31 \\
\hline$-1 \mathrm{a}$ & $\mathrm{DS} 1 \mathrm{a}+\mathrm{H}_{2} \rightarrow \mathrm{DR}+\mathrm{H}$ & $4.21 \times 10^{4}$ & 2.26 & 8.71 \\
\hline $1 b$ & $\mathrm{DR}+\mathrm{H} \rightarrow \mathrm{DS} 1 \mathrm{~b}+\mathrm{H}_{2}$ & $2.84 \times 10^{7}$ & 1.91 & 16.74 \\
\hline$-1 b$ & $\mathrm{DS} 1 \mathrm{~b}+\mathrm{H}_{2} \rightarrow \mathrm{DR}+\mathrm{H}$ & $5.33 \times 10^{4}$ & 2.26 & 9.85 \\
\hline $1 \mathrm{ab}$ & $\mathrm{DS} 1 \mathrm{a} \rightarrow \mathrm{DS} 1 \mathrm{~b}$ & $5.04 \times 10^{10}$ & 0.80 & 8.79 \\
\hline$-1 a b$ & $\mathrm{DS} 1 \mathrm{~b} \rightarrow \mathrm{DS} 1 \mathrm{a}$ & $6.14 \times 10^{10}$ & 0.81 & 9.48 \\
\hline $2 \mathrm{a}$ & $\mathrm{DS} 1 \mathrm{a} \rightarrow \mathrm{DS} 2 \mathrm{a}$ & $4.70 \times 10^{11}$ & 0.14 & 7.01 \\
\hline$-2 \mathrm{a}$ & $\mathrm{DS} 2 \mathrm{a} \rightarrow \mathrm{DS} 1 \mathrm{a}$ & $1.48 \times 10^{12}$ & 0.37 & 31.35 \\
\hline $2 b$ & $\mathrm{DS} 1 \mathrm{~b} \rightarrow \mathrm{DS} 2 \mathrm{~b}$ & $6.60 \times 10^{11}$ & 0.08 & 4.76 \\
\hline
\end{tabular}


Table 1: Continued from previous page.

\begin{tabular}{|c|c|c|c|c|}
\hline Number & Reaction & $A$ & $n$ & $E_{A}$ \\
\hline$-2 b$ & $\mathrm{DS} 2 \mathrm{~b} \rightarrow \mathrm{DS} 1 \mathrm{~b}$ & $5.13 \times 10^{12}$ & 0.34 & 28.48 \\
\hline $3 a$ & $\mathrm{DS} 2 \mathrm{a} \rightarrow \mathrm{DP}+\mathrm{H}$ & $6.42 \times 10^{9}$ & 1.09 & 32.34 \\
\hline$-3 a$ & $\mathrm{DP}+\mathrm{H} \rightarrow \mathrm{DS} 2 \mathrm{a}$ & $1.69 \times 10^{8}$ & 1.52 & 5.07 \\
\hline $3 b$ & $\mathrm{DS} 2 \mathrm{~b} \rightarrow \mathrm{DP}+\mathrm{H}$ & $2.06 \times 10^{10}$ & 1.10 & 31.91 \\
\hline$-3 b$ & $\mathrm{DP}+\mathrm{H} \rightarrow \mathrm{DS} 2 \mathrm{~b}$ & $1.73 \times 10^{8}$ & 1.49 & 4.54 \\
\hline $1 \mathrm{c}$ & $\mathrm{DR}+\mathrm{H} \rightarrow \mathrm{DS} 1 \mathrm{c}$ & $2.94 \times 10^{8}$ & 1.53 & 4.06 \\
\hline$-1 c$ & $\mathrm{DS} 1 \mathrm{c} \rightarrow \mathrm{DR}+\mathrm{H}$ & $1.95 \times 10^{10}$ & 1.07 & 34.30 \\
\hline $1 d$ & $\mathrm{DR}+\mathrm{H} \rightarrow \mathrm{DS} 1 \mathrm{~d}$ & $2.39 \times 10^{8}$ & 1.51 & 4.36 \\
\hline$-1 d$ & $\mathrm{DS} 1 \mathrm{~d} \rightarrow \mathrm{DR}+\mathrm{H}$ & $1.89 \times 10^{10}$ & 0.98 & 28.70 \\
\hline $2 \mathrm{c}$ & $\mathrm{DS} 1 \mathrm{c} \rightarrow \mathrm{DS} 2 \mathrm{c}$ & $7.96 \times 10^{11}$ & 0.43 & 20.65 \\
\hline$-2 c$ & $\mathrm{DS} 2 \mathrm{c} \rightarrow \mathrm{DS} 1 \mathrm{c}$ & $2.76 \times 10^{12}$ & 0.43 & 15.70 \\
\hline $2 \mathrm{~d}$ & $\mathrm{DS} 1 \mathrm{~d} \rightarrow \mathrm{DS} 2 \mathrm{~d}$ & $5.72 \times 10^{11}$ & 0.13 & 21.98 \\
\hline$-2 \mathrm{~d}$ & $\mathrm{DS} 2 \mathrm{~d} \rightarrow \mathrm{DS} 1 \mathrm{~d}$ & $2.17 \times 10^{12}$ & 0.50 & 18.75 \\
\hline $3 \mathrm{c}$ & $\mathrm{DS} 2 \mathrm{c} \rightarrow \mathrm{DS} 3 \mathrm{c}+\mathrm{H}$ & $4.15 \times 10^{10}$ & 1.08 & 35.82 \\
\hline$-3 c$ & $\mathrm{DS} 3 \mathrm{c}+\mathrm{H} \rightarrow \mathrm{DS} 2 \mathrm{c}$ & $3.72 \times 10^{8}$ & 1.53 & 0.00 \\
\hline $3 \mathrm{~d}$ & $\mathrm{DS} 2 \mathrm{~d} \rightarrow \mathrm{DS} 3 \mathrm{~d}+\mathrm{H}$ & $1.60 \times 10^{10}$ & 1.05 & 34.30 \\
\hline$-3 d$ & $\mathrm{DS} 3 \mathrm{~d}+\mathrm{H} \rightarrow \mathrm{DS} 2 \mathrm{~d}$ & $1.83 \times 10^{8}$ & 1.54 & 3.65 \\
\hline $4 \mathrm{c}$ & $\mathrm{DS} 3 \mathrm{c} \rightarrow \mathrm{DS} 4 \mathrm{c}+\mathrm{H}_{2}$ & $1.87 \times 10^{9}$ & 1.67 & 92.61 \\
\hline$-4 c$ & $\mathrm{DS} 4 \mathrm{c}+\mathrm{H}_{2} \rightarrow \mathrm{DS} 3 \mathrm{c}$ & $2.48 \times 10^{5}$ & 1.93 & 7.39 \\
\hline $4 \mathrm{~d}$ & $\mathrm{DS} 3 \mathrm{~d} \rightarrow \mathrm{DS} 4 \mathrm{~d}+\mathrm{H}_{2}$ & $1.67 \times 10^{9}$ & 1.62 & 102.02 \\
\hline$-4 d$ & $\mathrm{DS} 4 \mathrm{~d}+\mathrm{H}_{2} \rightarrow \mathrm{DS} 3 \mathrm{~d}$ & $5.68 \times 10^{5}$ & 1.92 & 15.60 \\
\hline $5 \mathrm{c}$ & $\mathrm{D} 4 \mathrm{c} \rightarrow \mathrm{DP}$ & $4.52 \times 10^{11}$ & 0.35 & 1.73 \\
\hline$-5 c$ & $\mathrm{DP} \rightarrow \mathrm{DS} 4 \mathrm{c}$ & $2.07 \times 10^{11}$ & 0.76 & 83.49 \\
\hline $5 \mathrm{~d}$ & $\mathrm{DS} 4 \mathrm{~d} \rightarrow \mathrm{DP}$ & $7.60 \times 10^{11}$ & 0.39 & 0.17 \\
\hline$-5 d$ & $\mathrm{DP} \rightarrow \mathrm{DS} 4 \mathrm{~d}$ & $8.17 \times 10^{10}$ & 0.78 & 85.59 \\
\hline $1 \mathrm{e}$ & $\mathrm{DR} \rightarrow \mathrm{DS} 1 \mathrm{e}$ & $1.60 \times 10^{1} 1$ & 0.78 & 83.23 \\
\hline$-1 e$ & $\mathrm{DS} 1 \mathrm{e} \rightarrow \mathrm{DR}$ & $3.05 \times 10^{11}$ & 0.29 & 0.08 \\
\hline $1 f$ & $\mathrm{DR} \rightarrow \mathrm{DS} 1 \mathrm{f}$ & $1.16 \times 10^{11}$ & 0.84 & 86.01 \\
\hline$-1 f$ & $\mathrm{DS} 1 \mathrm{f} \rightarrow \mathrm{DR}$ & $4.95 \times 10^{11}$ & 0.33 & 1.48 \\
\hline $2 \mathrm{e}$ & $\mathrm{DS} 1 \mathrm{e} \rightarrow \mathrm{DS} 2 \mathrm{e}$ & $2.49 \times 10^{11}$ & 0.12 & 11.62 \\
\hline
\end{tabular}


Table 1: Continued from previous page.

\begin{tabular}{|c|c|c|c|c|}
\hline Number & Reaction & $A$ & $n$ & $E_{A}$ \\
\hline$-2 \mathrm{e}$ & $\overline{\mathrm{DS}} 2 \mathrm{e} \rightarrow \mathrm{DS} 1 \mathrm{e}$ & $1.47 \times 10^{12}$ & 0.68 & 45.09 \\
\hline $2 f$ & $\mathrm{DS} 1 \mathrm{f} \rightarrow \mathrm{DS} 2 \mathrm{f}$ & $5.74 \times 10^{11}$ & 0.04 & 8.72 \\
\hline$-2 f$ & $\mathrm{DS} 2 \mathrm{f} \rightarrow \mathrm{DS} 1 \mathrm{f}$ & $2.16 \times 10^{12}$ & 0.29 & 18.61 \\
\hline $3 e$ & $\mathrm{DS} 2 \mathrm{e} \rightarrow \mathrm{DS} 3 \mathrm{e}$ & $1.40 \times 10^{11}$ & 0.58 & 27.01 \\
\hline$-3 e$ & $\mathrm{DS} 3 \mathrm{e} \rightarrow \mathrm{DS} 2 \mathrm{e}$ & $3.26 \times 10^{10}$ & 0.73 & 56.81 \\
\hline $3 f$ & $\mathrm{DS} 2 \mathrm{f} \rightarrow \mathrm{DS} 3 \mathrm{f}$ & $9.90 \times 10^{11}$ & 0.33 & 2.85 \\
\hline$-3 f$ & $\mathrm{DS} 3 \mathrm{f} \rightarrow \mathrm{DS} 2 \mathrm{f}$ & $1.02 \times 10^{11}$ & 0.87 & 57.11 \\
\hline $4 \mathrm{e}$ & $\mathrm{DS} 3 \mathrm{e} \rightarrow \mathrm{DS} 4 \mathrm{e}$ & $5.52 \times 10^{10}$ & 0.85 & 59.32 \\
\hline$-4 e$ & $\mathrm{DS} 4 \mathrm{e} \rightarrow \mathrm{DS} 3 \mathrm{e}$ & $7.57 \times 10^{10}$ & 0.67 & 38.56 \\
\hline $4 \mathrm{f}$ & DS3f $\rightarrow$ DS4f & $6.16 \times 10^{10}$ & 0.78 & 39.25 \\
\hline$-4 f$ & $\mathrm{DS} 4 \mathrm{f} \rightarrow \mathrm{DS} 3 \mathrm{f}$ & $9.57 \times 10^{10}$ & 0.70 & 35.20 \\
\hline $5 \mathrm{e}$ & $\mathrm{DS} 4 \mathrm{e} \rightarrow \mathrm{DP}+\mathrm{H}_{2}$ & $6.21 \times 10^{9}$ & 0.85 & 28.61 \\
\hline$-5 \mathrm{e}$ & $\mathrm{DP}+\mathrm{H}_{2} \rightarrow \mathrm{DS} 4 \mathrm{e}$ & $2.16 \times 10^{5}$ & 1.80 & 58.70 \\
\hline $5 f$ & $\mathrm{DS} 4 \mathrm{f} \rightarrow \mathrm{DP}+\mathrm{H}_{2}$ & $3.48 \times 10^{9}$ & 1.29 & 87.43 \\
\hline$-5 f$ & $\mathrm{DP}+\mathrm{H}_{2} \rightarrow \mathrm{DS} 4 \mathrm{f}$ & $1.70 \times 10^{5}$ & 2.09 & 95.63 \\
\hline 1 & $\mathrm{DR} \rightarrow \mathrm{DS} 1$ & $9.28 \times 10^{10}$ & 0.26 & 96.39 \\
\hline-1 & $\mathrm{DS} 1 \rightarrow \mathrm{DR}$ & $3.41 \times 10^{12}$ & 0.14 & 22.26 \\
\hline $2 \mathrm{~g}$ & $\mathrm{DS} 1 \rightarrow \mathrm{DS} 2 \mathrm{~g}$ & $5.37 \times 10^{10}$ & 0.75 & 42.64 \\
\hline$-2 g$ & $\mathrm{DS} 2 \mathrm{~g} \rightarrow \mathrm{DS} 1$ & $1.86 \times 10^{10}$ & 0.46 & 38.89 \\
\hline $2 \mathrm{~h}$ & $\mathrm{DS} 1 \rightarrow \mathrm{DS} 2 \mathrm{~h}$ & $2.75 \times 10^{11}$ & 0.47 & 13.93 \\
\hline$-2 h$ & $\mathrm{DS} 2 \mathrm{~h} \rightarrow \mathrm{DS} 1$ & $1.16 \times 10^{11}$ & 0.62 & 24.20 \\
\hline $3 \mathrm{~g}$ & $\mathrm{DS} 2 \mathrm{~g} \rightarrow \mathrm{DP}+\mathrm{H}_{2}$ & $1.07 \times 10^{11}$ & 0.53 & 22.31 \\
\hline$-3 g$ & $\mathrm{DP}+\mathrm{H}_{2} \rightarrow \mathrm{DS} 2 \mathrm{~g}$ & $1.06 \times 10^{5}$ & 1.94 & 89.66 \\
\hline $3 \mathrm{~h}$ & $\mathrm{DS} 2 \mathrm{~h} \rightarrow \mathrm{DS} 3 \mathrm{~h}$ & $1.01 \times 10^{11}$ & 0.71 & 25.39 \\
\hline$-3 h$ & $\mathrm{DS} 3 \mathrm{~h} \rightarrow \mathrm{DS} 2 \mathrm{~h}$ & $2.06 \times 10^{11}$ & 0.47 & 6.41 \\
\hline $4 \mathrm{~h}$ & $\mathrm{DS} 3 \mathrm{~h} \rightarrow \mathrm{DS} 4 \mathrm{~h}$ & $2.07 \times 10^{11}$ & 0.47 & 8.36 \\
\hline$-4 h$ & $\mathrm{DS} 4 \mathrm{~h} \rightarrow \mathrm{DS} 3 \mathrm{~h}$ & $5.21 \times 10^{10}$ & 0.73 & 39.11 \\
\hline $5 \mathrm{~h}$ & $\mathrm{DS} 4 \mathrm{~h} \rightarrow \mathrm{DS} 5 \mathrm{~h}$ & $1.64 \times 10^{11}$ & 0.61 & 28.35 \\
\hline$-5 h$ & $\mathrm{DS} 5 \mathrm{~h} \rightarrow \mathrm{DS} 4 \mathrm{~h}$ & $9.36 \times 10^{10}$ & 0.77 & 59.04 \\
\hline $6 \mathrm{~h}$ & $\mathrm{DS} 5 \mathrm{~h} \rightarrow \mathrm{DS} 6 \mathrm{~h}$ & $4.51 \times 10^{10}$ & 0.91 & 58.69 \\
\hline
\end{tabular}

Continued on next page. 
Table 1: Continued from previous page.

\begin{tabular}{ccccc} 
Number & Reaction & $A$ & $n$ & $E_{A}$ \\
\hline$-6 \mathrm{~h}$ & $\mathrm{DS} 6 \mathrm{~h} \rightarrow \mathrm{DS} 5 \mathrm{~h}$ & $3.93 \times 10^{10}$ & 0.80 & 43.03 \\
$7 \mathrm{~h}$ & $\mathrm{DS} 6 \mathrm{~h} \rightarrow \mathrm{DP}+\mathrm{H}_{2}$ & $6.30 \times 10^{09}$ & 1.19 & 81.67 \\
$-7 \mathrm{~h}$ & $\mathrm{DP}+\mathrm{H}_{2} \rightarrow \mathrm{DS} 6 \mathrm{~h}$ & $1.99 \times 10^{5}$ & 2.09 & 108.19 \\
\hline
\end{tabular}

\subsection{Kinetic simulations in a OD homogeneous reactor}

This section presents the results of the kinetic simulations of the seven-member ring formation studied in this work using the M06-2X/cc-pVTZ level of theory. As discussed in previous sections, the rates for the B3LYP $/ 6-311+\mathrm{G}(\mathrm{d}, \mathrm{p})$ level predicted very similar trends but generally the rates had higher absolute values for hydrogen abstractions, additions, and cyclisations and lower values for hydrogen migrations or losses. Figure 20 shows this for the seven-member ring formation on PAH A by a HACA sequence. The results from using the M06-2X/cc-pVTZ level are shown in a continuous line and the B3LYP $/ 6-311 \mathrm{G}+(\mathrm{d}, \mathrm{p})$ level in a dashed line. Since we expect the M06-2X/cc-pVTZ level of theory to give more accurate predictions for PAH chemistry we focus mostly on the kinetic simulations using these rate constants.

Figure 20 shows the results for the kinetic simulation for the seven-member ring formation on PAH A by a HACA sequence. This addition shows a rather weak temperature dependency with the reactant mole fraction decreasing after $1 \mathrm{~ms}$ for all cases and the corresponding products being formed after this time. The reversibility of this reaction system can also be observed in the figure with the conversion towards products being reduced at higher temperatures. The heptagon containing species appears to be the dominant product under the conditions studied, with the total mole fraction of the ethynyl-substituted products being at least an order of magnitude lower at all temperatures even though the the ethynyl-substituted products are present in higher concentrations at higher temperatures. Both pathways contribute towards the formation of the given products. 

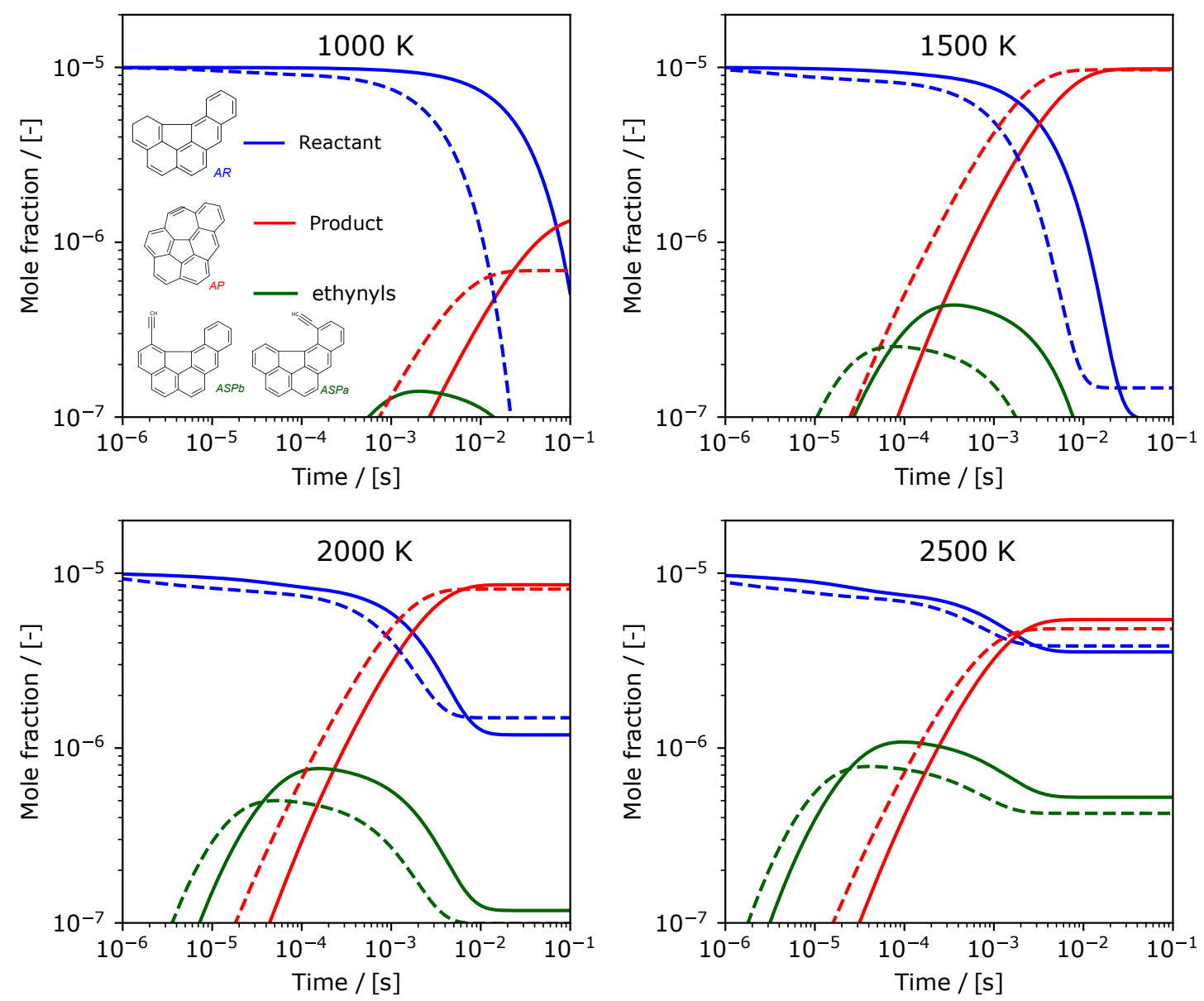

Figure 20: Kinetic simulation for the HACA seven-member ring formation on PAH A at different temperatures. The figure shows the results for the rate constants at the M06-2X/cc-pVTZ level of theory in a continuous line and the B3LYP $/ 6-311 \mathrm{G}+(\mathrm{d}, \mathrm{p})$ in a dashed line. The sum of the two ethynyl side products is plotted. The contribution of both HACA pathways studied are included together in this figure.

Figure 21 shows the results for the seven-member ring formation on PAH B by a HACA sequence followed by the rearrangement towards species BF, an RSR PAH with only six-member rings. For all the conditions studied, the five-seven-member ring pair containing product, $\mathrm{BP}$, appears to be an important intermediate that is likely to be observed at typical flame timescales of $1 \mathrm{~ms}$. This product proceeds to rearrange into $\mathrm{BF}$ via hydrogen addition at all conditions, with $\mathrm{BF}$ becoming the dominant product at longer timescales as well as higher temperatures. The ethynyl- 
substituted PAHs are observed at high temperatures, but it's concentration is again orders of magnitude lower than $\mathrm{BP}$ or BF. This acetylene addition shows a stronger temperature dependency with the mole fraction of reactant decreasing earlier in the high temperature simulations. The figure shows in dashed lines the mole fractions of the PAH reactant and products when only the high energy pathway, where the acetylene adds to the five-member ring (pathway a) is considered. Similarly, the dotted lines is for when only the low energy pathway where the acetylene adds to the six-member ring (pathway b). Pathway a appears to dominate the ring formation for this process in all the conditions studied.
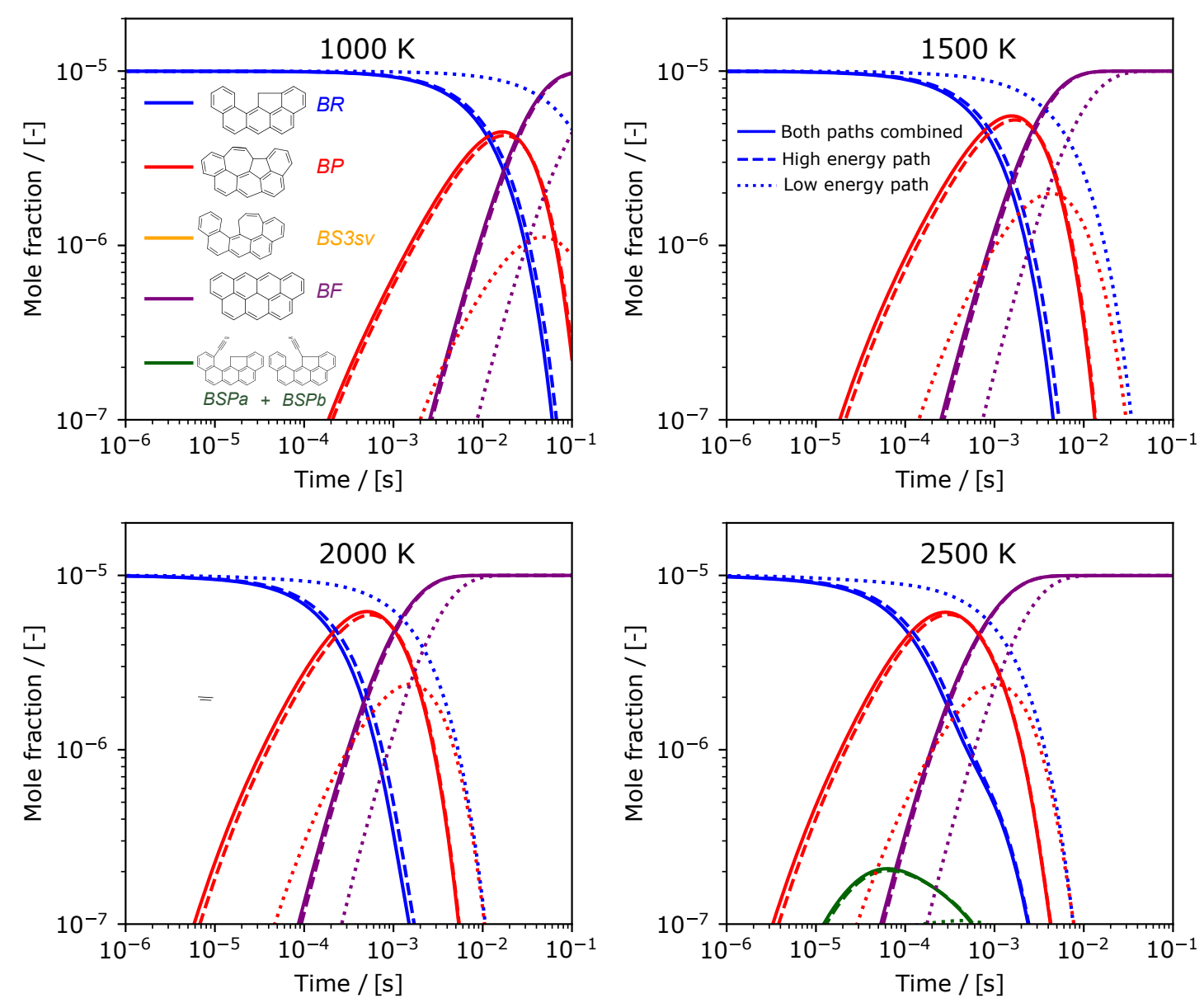

Figure 21: Kinetic simulation of the HACA seven-member ring formation on PAH B at different temperatures. Continuous lines show both pathways consuming the starting PAH simultaneously. Dashed lines show high energy pathway only. Dotted lines show low energy pathway only. 
The main explanation for this seems to be differences in the rate constants for the HACA sequences of both pathways. The hydrogen abstraction for the high energy pathway is faster than that of pathway $b$ as can be seen on the left panel of Figure 22. However, the acetylene addition rate constant for pathway a is lower in magnitude than that of pathway b. However, the reverse rate constant for pathway $b$ is at least three orders of magnitude higher than the forward rate constant at high temperatures. In the case of pathway a, the trend is similar but the forward and reverse rate constants are separated by only an order of magnitude making this addition faster as can be seen in the right panel of Fig. 22.
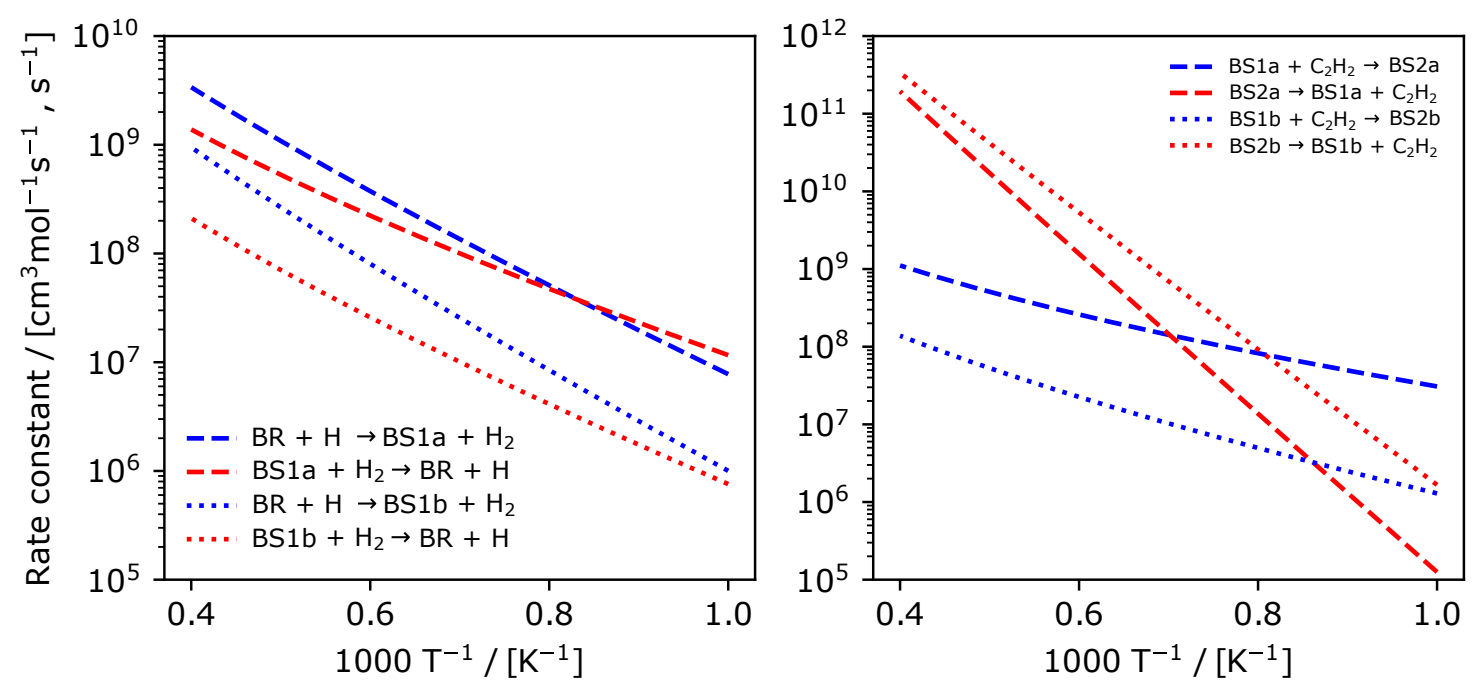

Figure 22: Forward and reverse rate constants of hydrogen abstraction (left) and acetylene addition (right) for pathway a (dashed lines) and pathway b (dotted lines) on PAH B. Units are $\mathrm{cm}^{3} \mathrm{~mol}^{-1} \mathrm{~s}^{-1}$ for bimolecular reactions and $\mathrm{s}^{-1}$ for unimolecular reactions.

In the case of bay closure reactions, the pathways presented in this work can be of importance under different conditions. Figure 23 shows the results of kinetic simulations for the consumption of $\mathrm{PAH} \mathrm{C}$ to form a seven-member ring product through all the different pathways (a to h) simultaneously. The figure shows that the hydrogen abstraction bay cyclisation is the route that contributes the most towards the consumption of the starting PAH for temperatures under $2000 \mathrm{~K}$. However, at temperatures around $2500 \mathrm{~K}$ the carbene route becomes the dominant pathway with a smaller contribution from the hydrogen abstraction route. This is in agreement with Xue and Scott [66] that suggested the carbene route as the most likely explanation to bond formation in PAH bay sites in the absence of radicals and high temperatures. 
The hydrogen addition bay closure and the direct cyclisation appear to be of less importance at the conditions studied. Figure 23 also shows that the timescale for the bay closure reaction for PAH C is lower than that of a carbon addition (e.g. the time for reactants to be consumed in Figures 20 and 21). A PAH containing a site like this will more likely form a seven-member ring before further carbon additions at neighbouring sites.
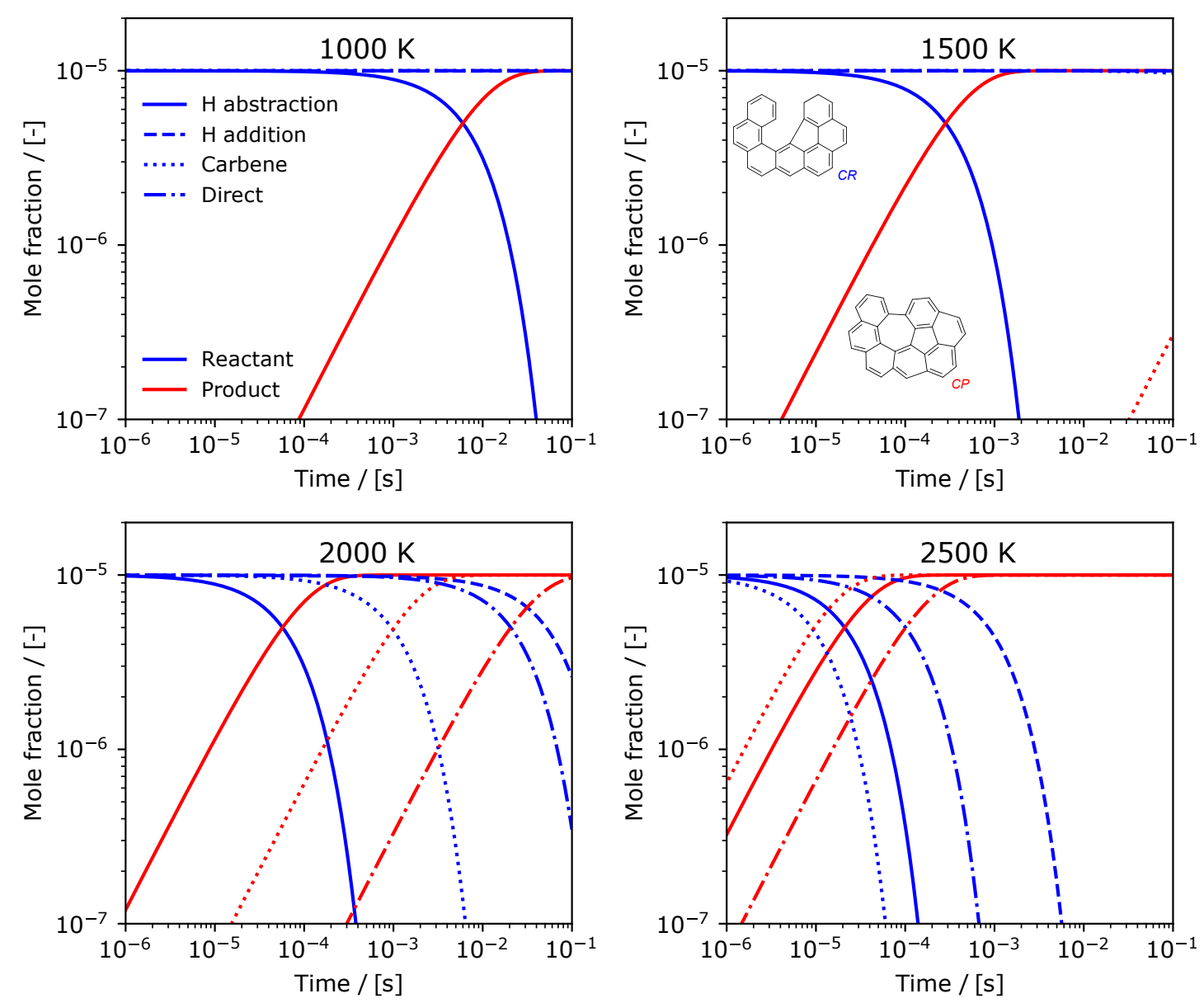

Figure 23: Kinetic simulations for the seven-member bay closure of PAH C at different temperatures. Each simulation is shown in different line pattern. Solid lines show hydrogen abstraction initiated bay closure, dashed lines show hydrogen addition assisted bay closure, dotted lines show the carbene cyclisation and dash-dotted lines show the direct cyclisation.

Figure 24 shows the results of the kinetic simulations of each available pathway 
consuming PAH D. The behaviour observed for this site is similar to that of PAH C. The figure shows that the hydrogen abstraction bay closure is the route that contributes the most towards the consumption of the starting PAH for temperatures under $2500 \mathrm{~K}$. After this temperature, the carbene route becomes the fastest pathway to produce of a seven-member ring, although the contribution from the hydrogen abstraction route is still significant. The hydrogen addition bay closure and the direct cyclisation for this site also appear to be slower for the conditions studied. The timescales for the bay closure for this site appear to be a few milliseconds slower than those of PAH C. 

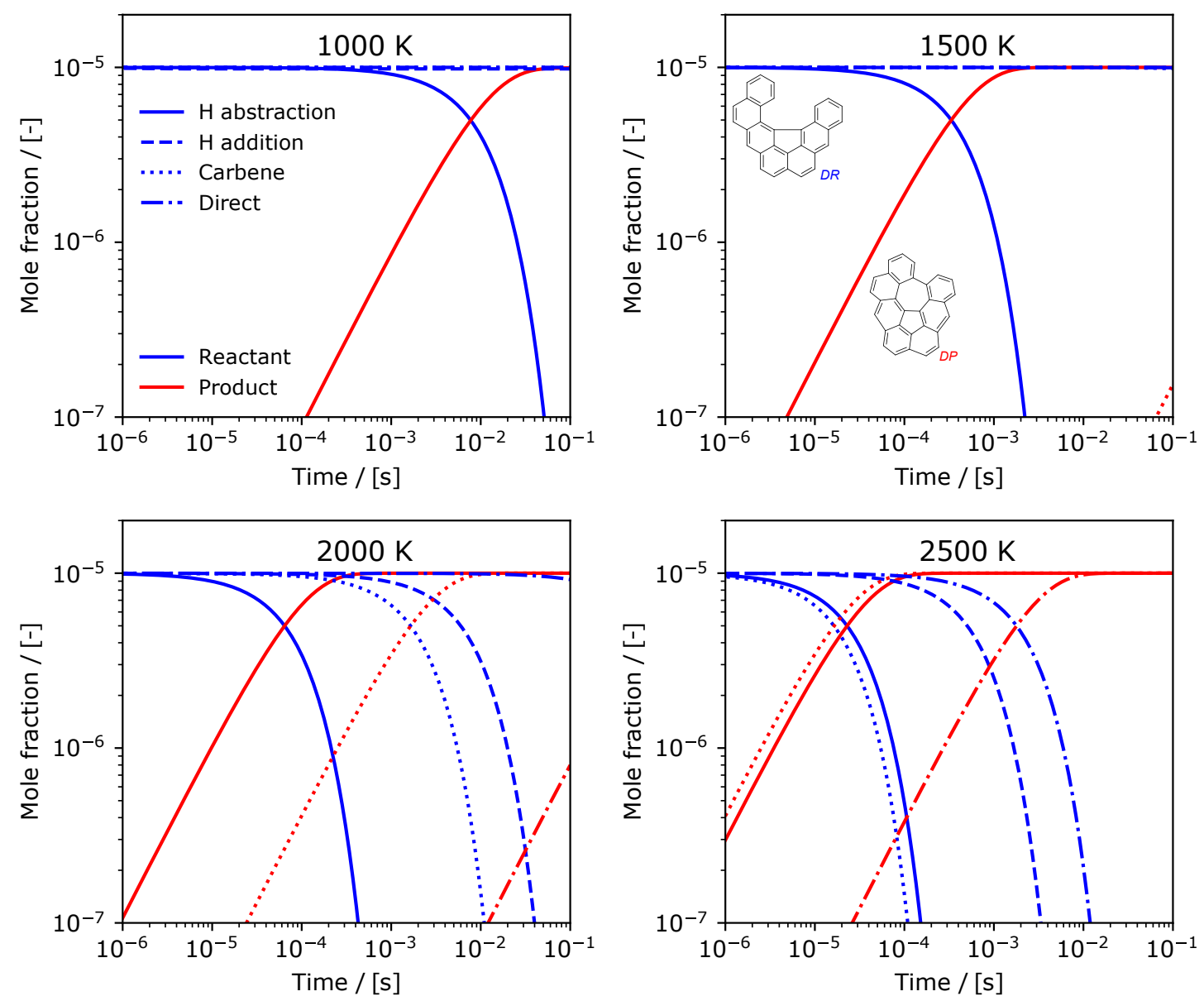

Figure 24: Kinetic simulations of the seven-member bay closure for PAH D at different temperatures. Each simulation is shown in different line pattern. Solid lines show hydrogen abstraction initiated bay closure, dashed lines show hydrogen addition assisted bay closure, dotted lines show the carbene cyclisation and dash-dotted lines show the direct cyclysation.

\section{Conclusions}

In this work, the kinetics of forming a seven member ring adjacent to a five member ring in PAHs have been studied by means of ab initio density functional theory calculations and kinetic simulations of $0 \mathrm{D}$ reactors at standard flame concentrations and a variety of temperatures. Density functional theory calculations were performed using the B3LYP $/ 6-311+\mathrm{G}(\mathrm{d}, \mathrm{p})$ level of theory for all geometry optmizations and frequency calculations. Additional single point energy calculations were performed 
at the M06-2X/cc-PVTZ level of theory in order to improve the estimates of energies and barrier heights for the computation of rate constants. In general, the barriers predicted by B3LYP and M06-2X are similar, with B3LYP tending to predict lower barriers for most processes.

The computed potential energy surfaces for the two HACA growths show that the formation of a seven member ring in a closed shell PAH (PAH A) and a resonancestabilized-radical PAH (PAH B) follows the same general trends even though the reaction energies are different. In both cases, the loss of hydrogen was seen to be the most difficult step. However, for PAH A, which carbon initially had its hydrogen abstracted was seen to be less significant compared to PAH B, where a clear high energy pathway and low energy pathway could be identified.

The computed potential energy surfaces for the four bay closure routes for PAH C and PAH D were seen to be generally similar for the hydrogen abstraction and addition routes, with atomic hydrogen and $\mathrm{H}_{2}$ losses seen to be the most difficult steps. For both routes and PAHs, there was not much dependence on the initial carbon attacked by the hydrogen radical. The bay closures via carbene formations for PAH C and PAH D both required several hydrogen migrations to occur before $\mathrm{H}_{2}$ and there was a noticeable difference depending on which carbon atom forms the initial carbene site, again resulting in higher energy and lower energy routes. The direct cyclisation was the one route where PAH C and PAH D are completely different, with $\mathrm{PAH} \mathrm{C}$ able to undergo $\mathrm{H}_{2}$ loss directly after cyclisation, but PAH D requiring several migrations before this can occur.

The kinetic simulations in 0D homogeneous reactors for PAH A showed that the trends in predicted product formation are the same for both the B3LYP/6$311+\mathrm{G}(\mathrm{d}, \mathrm{p})$ and M06-2X/cc-pVTZ computed energies, with the seven-member ring containing product formation being slower for the latter level of theory. This is expected given the higher predicted barriers and lower rate constants. In addition, both pathways contributed to the product formation, which is expected as they were rather similar. The kinetic simulations for PAH B show that the high energy pathway is the main contributor to the product formation, due to the lower reversibility of the acetylene addition step. For the bay closures, the hydrogen abstraction facilitated bay closure was seen to be the main contributor to seven-member ring formation at 1000,1500 , and $2000 \mathrm{~K}$. At $2500 \mathrm{~K}$, the carbene route becomes the dominant contributor, suggesting this pathway could be important at very high temperatures. In general, the HACA growth and bay closure processes did occur to some extent at all temperatures, suggesting seven-member ring formation in PAHs already containing five-member rings could be important. 


\section{Acknowledgements}

This research is supported by the National Research Foundation, Prime Minister's Office, Singapore under its under its Campus for Research Excellence and Technological Enterprise (CREATE) programme. AM gratefully acknowledges Johnson Matthey for financial support. GL is funded by a CONACYT Cambridge Scholarship and wishes to acknowledge both institutions, the National Council of Science and Technology and the Cambridge Commonwealth Trust. MK gratefully acknowledges the support of the Alexander von Humboldt foundation.

\section{References}

[1] M. Bachmann, W. Wiese, K.-H. Homann, PAH and aromers: Precursors of fullerenes and soot, Symposium (International) on Combustion 26 (1996) 2259 - 2267. doi:10.1016/S0082-0784(96)80053-1.

[2] H. Wang, M. Frenklach, A detailed kinetic modeling study of aromatics formation in laminar premixed acetylene and ethylene flames, Combustion and Flame 110 (1997) 173 - 221. doi:10.1016/S0010-2180(97)00068-0.

[3] M. Frenklach, Reaction mechanism of soot formation in flames, Physical Chemistry Chemical Physics 4 (2002) 2028-2037. doi:10.1039/B110045A.

[4] H. Wang, Formation of nascent soot and other condensed-phase materials in flames, Proceedings of the Combustion Institute 33 (2011) 41-67. doi:10.1016/ j.proci.2010.09.009.

[5] P. J. Landrigan, R. Fuller, N. J. R. Acosta, O. Adeyi, R. Arnold, N. N. Basu, A. B. Baldé, R. Bertollini, S. Bose-O’Reilly, J. I. Boufford, P. N. Breysse, T. Chiles, C. Mahidol, A. M. Coll-Seck, M. L. Cropper, J. Fobil, V. Fuster, M. Greenstone, A. Haines, D. Hanrahan, D. Hunter, M. Khare, A. Krupnick, B. Lanphear, B. Lohani, K. Martin, K. V. Mathiasen, M. A. McTeer, C. J. L. Murray, J. D. Ndahimananjara, F. Perera, J. Potočnik, A. S. Preker, J. Ramesh, J. Rockström, C. Salinas, L. D. Samson, K. Sandilya, P. D. Sly, K. R. Smith, A. Steiner, R. B. Stewart, W. A. Suk, O. C. P. van Schayck, G. N. Yadama, K. Yumkella, M. Zhong, The Lancet Commission on pollution and health, Lancet (2017).

[6] J. R. McConnell, R. Edwards, G. L. Kok, M. G. Flanner, C. S. Zender, E. S. Saltzman, J. R. Banta, D. R. Pasteris, M. M. Carter, J. D. W. Kahl, 20th- 
Century industrial black carbon emissions altered arctic climate forcing, Science 317 (2007) 1381-1384. doi:10.1126/science. 1144856.

[7] T. C. Bond, S. J. Doherty, D. W. Fahey, P. M. Forster, T. Berntsen, B. J. Deangelo, M. G. Flanner, S. Ghan, B. Kärcher, D. Koch, S. Kinne, Y. Kondo, P. K. Quinn, M. C. Sarofim, M. G. Schultz, M. Schulz, C. Venkataraman, H. Zhang, S. Zhang, N. Bellouin, S. K. Guttikunda, P. K. Hopke, M. Z. Jacobson, J. W. Kaiser, Z. Klimont, U. Lohmann, J. P. Schwarz, D. Shindell, T. Storelvmo, S. G. Warren, C. S. Zender, Bounding the role of black carbon in the climate system: A scientific assessment, Journal of Geophysical Research 118 (2013) 5380-5552. doi:10.1002/jgrd.50171.

[8] T. C. Bond, H. Sun, Can reducing black carbon emissions counteract global warming?, Environmental Science \& Technology 39 (2005) 5921-5926. doi:10. 1021/es0480421.

[9] R. Agarwal, A. Awasthi, N. Singh, S. K. Mittal, P. K. Gupta, Epidemiological study on healthy subjects affected by agriculture crop-residue burning episodes and its relation with their pulmonary function tests, International Journal of Environmental Health Research 23 (2013) 281-295. doi:10.1080/09603123.2012. 733933.

[10] R. Niranjan, A. K. Thakur, The toxicological mechanisms of environmental soot (black carbon) and carbon black: focus on oxidative stress and inflammatory pathways, Frontiers in Immunology 8 (2017) 763. doi:10.3389/fimmu.2017. 00763.

[11] A. G. Tielens, Interstellar polycyclic aromatic hydrocarbon molecules, Annual Review of Astronomy and Astrophyics. 46 (2008) 289-337. doi:10.1146/ annurev .astro.46.060407.145211.

[12] P. Lavvas, M. Sander, M. Kraft, H. Imanaka, Surface chemistry and particle shape: processes for the evolution of aerosols in Titan's atmosphere, The Astrophysical Journal 728 (2011) 80. doi:10.1088/0004-637X/728/2/80.

[13] L. Zhao, R. I. Kaiser, B. Xu, U. Ablikim, M. Ahmed, M. M. Evseev, E. K. Bashkirov, V. N. Azyazov, A. M. Mebel, Low-temperature formation of polycyclic aromatic hydrocarbons in Titan's atmosphere, Nature Astronomy 2 (2018) 973. doi:10.1038/s41550-018-0585-y. 
[14] M. Ezawa, Metallic graphene nanodisks: Electronic and magnetic properties, Physical Review B 76 (2007) 245415. doi:10.1103/PhysRevB.76.245415.

[15] S. Stein, On the high temperature chemical equilibria of polycyclic aromatic hydrocarbons, The Journal of Physical Chemistry 82 (1978) 566-571. doi:10. $1021 / j 100494 a 600$.

[16] M. Frenklach, D. W. Clary, W. C. Gardiner Jr, S. E. Stein, Detailed kinetic modeling of soot formation in shock-tube pyrolysis of acetylene, Symposium (International) on Combustion, [Proceedings] 20 (1985) 887-901. doi:10.1016/ S0082-0784(85)80578-6.

[17] M. Frenklach, H. Wang, Detailed modeling of soot particle nucleation and growth, Symposium (International) on Combustion, [Proceedings] 23 (1991) 1559-1566. doi:10.1016/S0082-0784(06) 80426-1.

[18] E. Georganta, R. K. Rahman, A. Raj, S. Sinha, Growth of polycyclic aromatic hydrocarbons (PAHs) by methyl radicals: Pyrene formation from phenanthrene, Combustion and Flame 185 (2017) 129-141. doi:10.1016/j.combustflame. 2017.07.011.

[19] S. Sinha, A. Raj, Polycyclic aromatic hydrocarbon (PAH) formation from benzyl radicals: a reaction kinetics study, Physical Chemistry Chemical Physics 18 (2016) 8120-8131. doi:10.1039/C5CP06465A.

[20] A. M. Mebel, R. I. Kaiser, Formation of resonantly stabilised free radicals via the reactions of atomic carbon, dicarbon, and tricarbon with unsaturated hydrocarbons: theory and crossed molecular beams experiments, International Reviews in Physical Chemistry 34 (2015) 461-514. doi:10.1080/0144235X. 2015. 1075280 .

[21] S. Sinha, R. K. Rahman, A. Raj, On the role of resonantly stabilized radicals in polycyclic aromatic hydrocarbon (PAH) formation: pyrene and fluoranthene formation from benzyl-indenyl addition, Physical Chemistry Chemical Physics 19 (2017) 19262-19278. doi:10.1039/C7CP02539D.

[22] P. Liu, Z. Li, A. Bennett, H. Lin, S. M. Sarathy, W. L. Roberts, The site effect on PAHs formation in HACA-based mass growth process, Combustion and Flame 199 (2019) 54-68. doi:10.1016/j .combustflame.2018.10.010. 
[23] M. Frenklach, R. I. Singh, A. M. Mebel, On the low-temperature limit of HACA, Proceedings of the Combustion Institute 37 (2019) 969-976. doi:10. 1016/j.proci.2018.05.068.

[24] V. Kislov, N. Islamova, A. Kolker, S. Lin, A. Mebel, Hydrogen abstraction acetylene addition and Diels - Alder mechanisms of PAH formation: A detailed study using first principles calculations, Journal of Chemical Theory and Computation 1 (2005) 908-924. doi:10.1021/ct0500491.

[25] X. You, R. Whitesides, D. Zubarev, W. A. Lester Jr, M. Frenklach, Bay-capping reactions: Kinetics and influence on graphene-edge growth, Proceedings of the Combustion Institute 33 (2011) 685-692. doi:10.1016/j .proci.2010.05.110.

[26] R. Whitesides, M. Frenklach, Detailed kinetic Monte Carlo simulations of graphene-edge growth, The Journal of Physical Chemistry A 114 (2009) 689703.

[27] A. Violi, A. F. Sarofim, G. A. Voth, Kinetic Monte Carlo-molecular dynamics approach to model soot inception, Combustion Science and Technology 176 (2004) 991-1005. doi:10.1080/00102200490428594.

[28] A. Raj, M. Celnik, R. Shirley, M. Sander, R. Patterson, R. West, M. Kraft, A statistical approach to develop a detailed soot growth model using pah characteristics, Combustion and Flame 156 (2009) 896-913. doi:10.1016/j. combustflame.2009.01.005.

[29] E. K. Yapp, C. G. Wells, J. Akroyd, S. Mosbach, R. Xu, M. Kraft, Modelling PAH curvature in laminar premixed flames using a detailed population balance model, Combustion and Flame 176 (2017) 172-180. doi:10.1016/j. combustflame.2016.10.004.

[30] A. Violi, Cyclodehydrogenation reactions to cyclopentafused polycyclic aromatic hydrocarbons, The Journal of Physical Chemistry A 109 (2005) 7781-7787. doi:10.1021/jp052384r.

[31] L. Zhao, M. Prendergast, R. I. Kaiser, B. Xu, U. Ablikim, W. Lu, M. Ahmed, A. D. Oleinikov, V. N. Azyazov, A. H. Howlader, et al., How to add a fivemembered ring to polycyclic aromatic hydrocarbons (PAHs)-molecular mass growth of the 2-naphthyl radical $\left(\mathrm{C}_{10} \mathrm{H}_{7}\right)$ to benzindenes $\left(\mathrm{C}_{13} \mathrm{H}_{10}\right)$ as a case study, Physical Chemistry Chemical Physics 21 (2019) 16737-16750. doi:10. 1039/C9CP02930C. 
[32] J.W. Martin, R.I. Slavchov, E.K.Y Yapp, J. Akroyd, S. Mosbach, M. Kraft, The polarization of polycyclic aromatic hydrocarbons curved by pentagon incorporation: The role of the flexoelectric dipole, Journal of Physical Chemistry C 121 (2017) 27154-27163. doi:10.1021/acs.jpcc .7b09044.

[33] J. W. Martin, M. Botero, R. I. Slavchov, K. Bowal, J. Akroyd, S. Mosbach, M. Kraft, Flexoelectricity and the formation of carbon nanoparticles in flames, The Journal of Physical Chemistry C 122 (2018) 22210-22215. doi:10.1021/ acs.jpcc. 8b08264.

[34] J. W. Martin, Polar curved polycyclic aromatic hydrocarbons in soot formation, Proceedings of the Combustion Institute 37 (2019) 1117 - 1123. doi:10.1016/ j.proci.2018.05.046.

[35] A. Raj, S. Y. Yang, D. Cha, R. Tayouo, S. H. Chung, Structural effects on the oxidation of soot particles by $\mathrm{O}_{2}$ : Experimental and theoretical study, Combustion and Flame 160 (2013) 1812-1826. doi:10.1016/j . combustf lame.2013.03.010.

[36] R. Singh, M. Frenklach, A mechanistic study of the influence of graphene curvature on the rate of high-temperature oxidation by molecular oxygen, Carbon 101 (2016) 203 - 212. doi:10.1016/j. carbon.2016.01.090.

[37] A. Raj, Structural effects on the growth of large polycyclic aromatic hydrocarbons by $\mathrm{C}_{2} \mathrm{H}_{2}$, Combustion and Flame 204 (2019) 331-340. doi:10.1016/j. combustflame.2019.03.027.

[38] I. R. Márquez, S. Castro-Fernández, A. Millán, A. G. Campaña, Synthesis of distorted nanographenes containing seven-and eight-membered carbocycles, Chemical Communications 54 (2018) 6705-6718. doi:10.1039/C8CC02325E.

[39] E. U. Mughal, D. Kuck, Merging tribenzotriquinacene with hexa-perihexabenzocoronene: a cycloheptatriene unit generated by Scholl reaction, Chemical Communications 48 (2012) 8880-8882. doi:10.1039/C2CC34245F.

[40] P. Schwerdtfeger, L. N. Wirz, J. Avery, The topology of fullerenes, Wiley Interdisciplinary Reviews: Computational Molecular Science 5 (2015) 96-145. doi:10.1002/wcms . 1207.

[41] B. Eggen, M. Heggie, G. Jungnickel, C. Latham, R. Jones, P. Briddon, Autocatalysis during fullerene growth, Science 272 (1996) 87-90. doi:10.1126/ science.272.5258.87. 
[42] C. Ewels, M. Heggie, P. Briddon, Adatoms and nanoengineering of carbon, Chemical Physics Letters 351 (2002) 178-182. doi:10.1016/S0009-2614(01) 01371-9.

[43] J. Ma, D. Alfè, A. Michaelides, E. Wang, Stone-Wales defects in graphene and other planar sp2-bonded materials, Physical Review B 80 (2009) 033407. doi:10.1103/PhysRevB.80.033407.

[44] L. T. Scott, Fragments of fullerenes: novel syntheses, structures and reactions, Pure and applied chemistry 68 (1996) 291-300. doi:10.1351/pac199668020291.

[45] V. Kislov, A. Sadovnikov, A. Mebel, Formation mechanism of polycyclic aromatic hydrocarbons beyond the second aromatic ring, The Journal of Physical Chemistry A 117 (2013) 4794-4816.

[46] J. W. Martin, C. de Tomas, I. Suarez-Martinez, M. Kraft, N. A. Marks, Topology of disordered 3D graphene networks, Physical Review Letters 123 (2019) 116105. doi:10.1103/PhysRevLett.123.116105.

[47] A. C. Forse, J. M. Griffin, V. Presser, Y. Gogotsi, C. P. Grey, Ring current effects: factors affecting the NMR chemical shift of molecules adsorbed on porous carbons, The Journal of Physical Chemistry C 118 (2014) 7508-7514. doi:10. 1021/jp502387x.

[48] A. C. Forse, C. Merlet, P. K. Allan, E. K. Humphreys, J. M. Griffin, M. Aslan, M. Zeiger, V. Presser, Y. Gogotsi, C. P. Grey, New insights into the structure of nanoporous carbons from nmr, raman, and pair distribution function analysis, Chemistry of Materials 27 (2015) 6848-6857.

[49] Q. Mao, A. C. van Duin, K. Luo, Formation of incipient soot particles from polycyclic aromatic hydrocarbons: A ReaxFF molecular dynamics study, Carbon 121 (2017) 380 - 388. doi:10.1016/j . carbon.2017.06.009.

[50] Q. Mao, K. H. Luo, Trace metal assisted polycyclic aromatic hydrocarbons fragmentation, growth and soot nucleation, Proceedings of the Combustion Institute 37 (2019) 1023-1030. doi:10.1016/j.proci.2018.06.106.

[51] B. Saha, S. Irle, K. Morokuma, Formation mechanism of polycyclic aromatic hydrocarbons in benzene combustion: Quantum chemical molecular dynamics simulations, The Journal of Chemical Physics 132 (2010) 224303. doi:10.1063/ 1.3447895 . 
[52] A. Ricca, C. W. Bauschlicher Jr, L. J. Allamandola, The infrared spectroscopy of polycyclic aromatic hydrocarbons with five-and seven-membered fused ring defects, The Astrophysical Journal 729 (2011) 94. doi:10.1088/0004-637X/ $729 / 2 / 94$.

[53] K. Johansson, M. Head-Gordon, P. Schrader, K. Wilson, H. Michelsen, Resonance-stabilized hydrocarbon-radical chain reactions may explain soot inception and growth, Science 361 (2018) 997-1000. doi:10.1126/science. aat3417.

[54] M. Commodo, K. Kaiser, G. De Falco, P. Minutolo, F. Schulz, A. D'Anna, L. Gross, On the early stages of soot formation: Molecular structure elucidation by high-resolution atomic force microscopy, Combustion and Flame 205 (2019) 154-164. doi:10.1016/j . combustf lame.2019.03.042.

[55] B. Temelso, C. D. Sherrill, R. C. Merkle, R. A. Freitas, High-level ab initio studies of hydrogen abstraction from prototype hydrocarbon systems, The Journal of Physical Chemistry A 110 (2006) 11160-11173. doi:10.1021/jp061821e.

[56] D. Hou, X. You, Reaction kinetics of hydrogen abstraction from polycyclic aromatic hydrocarbons by $\mathrm{H}$ atoms, Physical Chemistry Chemical Physics 19 (2017) 30772-30780. doi:10.1039/C7CP04964A.

[57] Y. Zhao, D. G. Truhlar, How well can new-generation density functionals describe the energetics of bond-dissociation reactions producing radicals?, The Journal of Physical Chemistry A 112 (2008) 1095-1099.

[58] M. Frisch, G. Trucks, H. Schlegel, G. Scuseria, M. Robb, J. Cheeseman, G. Scalmani, V. Barone, G. Petersson, H. Nakatsuji, et al., Gaussian 16, Revision A 3 (2016).

[59] C. W. Gao, J. W. Allen, W. H. Green, R. H. West, Reaction Mechanism Generator: Automatic construction of chemical kinetic mechanisms, Computer Physics Communications 203 (2016) 212-225. doi:doi.org/10.1016/j.cpc.2016.02. 013.

[60] E. Wigner, On the quantum correction for thermodynamic equilibrium, Physical Review 40 (1932) 749-759. doi:10.1103/PhysRev.40.749.

[61] D. G. Truhlar, A. Kuppermann, Exact tunneling calculations, Journal of the American Chemical Society 93 (1971) 1840-1851. doi:10.1021/ja00737a002. 
[62] S. Canneaux, F. Bohr, E. Henon, Kisthelp: A program to predict thermodynamic properties and rate constants from quantum chemistry results, Journal of computational chemistry 35 (2014) 82-93.

[63] H. Wang, M. Frenklach, Transport properties of polycyclic aromatic hydrocarbons for flame modeling, Combustion and flame 96 (1994) 163-170.

[64] S. Fascella, C. Cavallotti, R. Rota, S. Carrà, The peculiar kinetics of the reaction between acetylene and the cyclopentadienyl radical, The Journal of Physical Chemistry A 109 (2005) 7546-7557.

[65] A. E. Long, S. S. Merchant, A. G. Vandeputte, H.-H. Carstensen, A. J. Vervust, G. B. Marin, K. M. Van Geem, W. H. Green, Pressure dependent kinetic analysis of pathways to naphthalene from cyclopentadienyl recombination, Combustion and Flame 187 (2018) 247-256.

[66] X. Xue, L. T. Scott, Thermal cyclodehydrogenations to form 6-membered rings: Cyclizations of [5]helicenes, Organic Letters 9 (2007) 3937-3940. doi:10.1021/ ol7015516. 